\title{
MODELING GPR DATA TO INTERPRET POROSITY AND DNAPL SATURATIONS FOR CALIBRATION OF A 3-D MULTIPHASE FLOW SIMULATION
}

\section{Open-File Report 02-451}
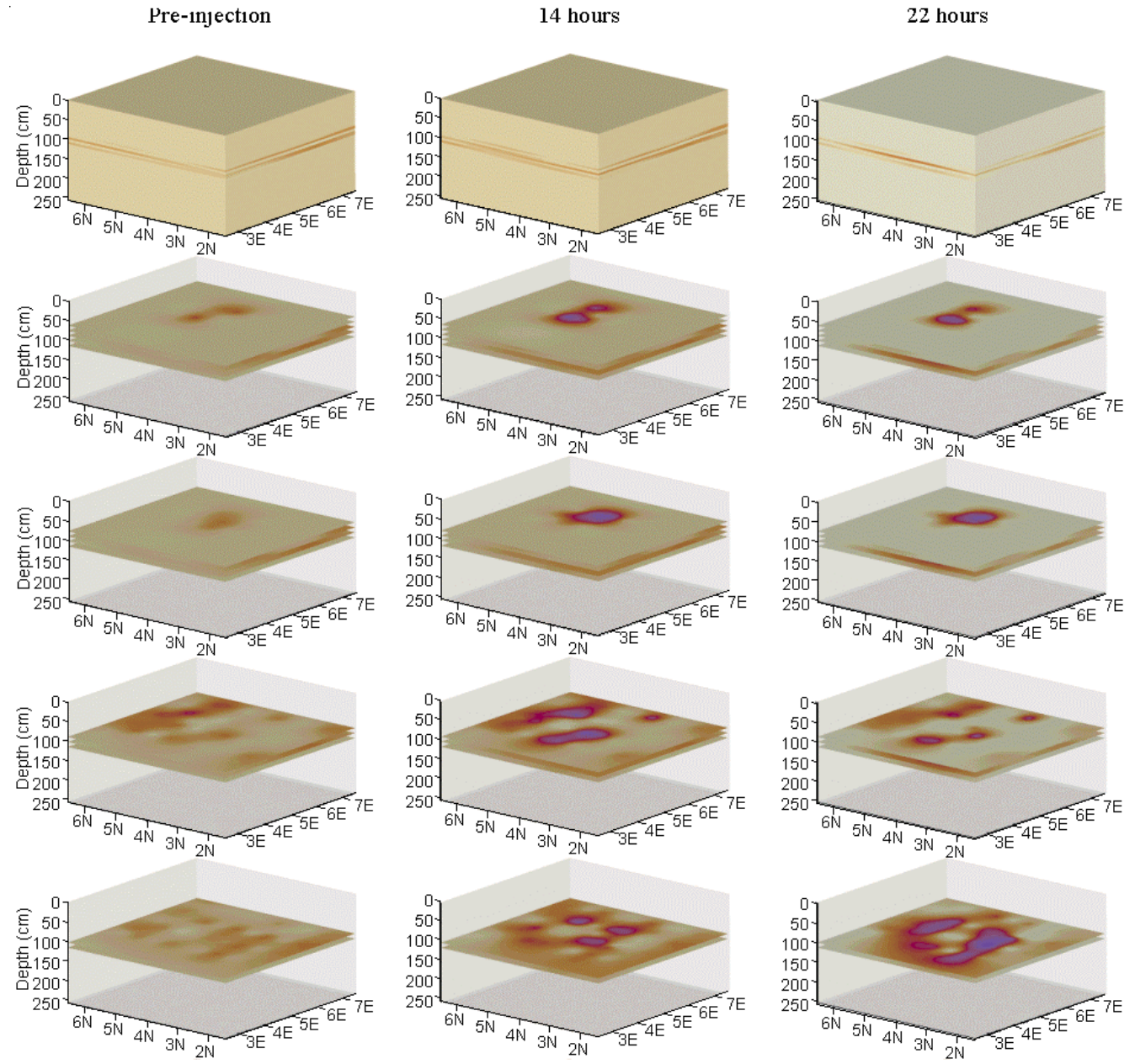

\section{U.S. Department of the Interior U.S. Geological Survey}

This report is preliminary and has not been reviewed for conformity with U.S. Geological Survey editorial standards nor with the North American Stratigraphic Code. Any use of trade names in this publication is for descriptive purposes only and does not imply endorsement by the U.S. Government. 


\section{MODELING GPR DATA TO INTERPRET POROSITY AND DNAPL SATURATIONS FOR CALIBRATION OF A 3-D MULTIPHASE FLOW SIMULATION}

By Kristen W. Sneddon ${ }^{1}$, Michael H. Powers ${ }^{1}$, Raymond H. Johnson ${ }^{1,2}$, and Eileen P. Poeter ${ }^{2}$

U.S. GEOLOGICAL SURVEY

Open-File Report 02-451

Denver, Colorado

2002

\footnotetext{
${ }^{1}$ U.S. Geological Survey, Denver CO

${ }^{2}$ Colorado School of Mines, Golden, CO
} 


\section{U.S. DEPARTMENT OF THE INTERIOR \\ BRUCE BABBITT, Secretary \\ U.S. GEOLOGICAL SURVEY \\ Charles G. Groat, Director}

The use of trade, product, industry, or firm names is for descriptive purposes only and does not imply endorsement by the U.S. Government.

For additional information write to:

U.S. Geological Survey

Box 25046, Mail Stop 413

Denver Federal Center

Denver, CO 50225-0046
Copies of this report can be

can be purchased from:

U.S. Geological Survey

Branch of Information Services

Box 25286

Denver, CO 50225-0425 


\title{
MODELING GPR DATA TO INTERPRET POROSITY AND DNAPL SATURATIONS FOR CALIBRATION OF A 3-D MULTIPHASE FLOW SIMULATION
}

\author{
By Kristen W. Sneddon, Michael H. Powers, Raymond H. Johnson, and Eileen P. Poeter
}

\begin{abstract}
Dense nonaqueous phase liquids (DNAPLs) are a pervasive and persistent category of groundwater contamination. In an effort to better understand their unique subsurface behavior, a controlled and carefully monitored injection of PCE (perchloroethylene), a typical DNAPL, was performed in conjunction with the University of Waterloo at Canadian Forces Base Borden in 1991. Of the various geophysical methods used to monitor the migration of injected PCE, the U.S. Geological Survey collected $500-\mathrm{MHz}$ ground penetrating radar (GPR) data. These data are used in determining calibration parameters for a multiphase flow simulation.

GPR data were acquired over time on a fixed two-dimensional surficial grid as the DNAPL was injected into the subsurface. Emphasis is on the method of determining DNAPL saturation values from this time-lapse GPR data set. Interactive full-waveform GPR modeling of regularized field traces resolves relative dielectric permittivity versus depth profiles for pre-injection and later-time data. Modeled values are end members in recursive calculations of the Bruggeman-Hanai-Sen (BHS) mixing formula, yielding interpreted pre-injection porosity and post-injection DNAPL saturation values. The resulting interpreted physical properties of porosity and DNAPL saturation of the Borden test cell, defined on a grid spacing of $50 \mathrm{~cm}$ with $1-\mathrm{cm}$ depth resolution, are used as observations for calibration of a 3-D multiphase flow simulation. Calculated values of DNAPL saturation in the subsurface at 14 and 22 hours after the start of injection, from both the GPR and the multiphase flow modeling, are interpolated volumetrically and presented for visual comparison.
\end{abstract}

\section{INTRODUCTION}

Due to unique physical properties of dense nonaqueous phase liquids (DNAPLs), characterization and remediation of DNAPL contamination is a challenging problem (Pankow and others 1996). When introduced into the subsurface, DNAPLs migrate primarily in response to gravity as a discrete liquid phase from groundwater, resulting in a flow pattern more tightly coupled to geological heterogeneity than to groundwater flow (Sander and others 1992). DNAPLs have relatively low viscosity, low degradability and low solubility in water, so they can move to depth quickly to act as persistant contaminant sources for large quantities of groundwater. The small amounts of contaminant that do dissolve (parts per billion) are orders of magnitude above EPA-established maximum concentration limits for drinking water. Extensive research in recent years has been devoted to improved characterization of DNAPL-contaminated sites and understanding of the processes governing DNAPL movement.

In efforts to better understand and predict complex physical processes, numerical simulation models are widely used in the earth sciences. Though it is not possible to truly validate simulation models of natural systems (Oreskes and others 1994), it is advantageous to strive for an optimized fit of simulation predictions to available data observations in anticipation of evaluating and improving our hypotheses regarding DNAPL behavior. Using the first 22 hours of time-lapse $500-\mathrm{MHz} \mathrm{GPR}$ data acquired during the controlled perchloroethylene (PCE) injection at Canadian Forces Base Borden in 1991, this paper describes a procedure to interpret GPR data for pre-injection porosity and subsequent DNAPL saturations for use as calibration parameters for multiphase flow simulation (Figure 1). 
Closeness-of-fit evaluation of the multiphase flow simulation results to the GPR-derived calibration data guides the development of our hypotheses regarding processes governing DNAPL flow in the Borden test cell.

The ability of GPR to detect DNAPL in the subsurface and to be used in calculating saturation values relies on the availability of time-lapse data including the pre-injection or pre-release condition. For a single time snapshot of GPR data, variations in relative dielectric permittivity may be due to variation in pre-existing layer porosity or possibly due to the presence of DNAPL in the subsurface. DNAPL cannot be recognized directly in GPR data until it is seen to move through inspection of time-lapse data sets. When time-lapse data are available, DNAPL saturation and pre-release porosity can be quantified through iterative applications of the Bruggeman-Hanai-Sen (BHS) mixing formula (Bruggeman 1935; Hanai 1968; Sen and others 1981) applied to the dielectric properties interpreted from electromagnetic modeling of the GPR data (Figure 1). These values are then available to estimate hydraulic permeability fields through iterative inversion of multiphase flow simulations.

\section{GEOPHYSICAL DETECTION OF PCE IN THE BORDEN CELL}

\section{The Borden Cell}

A controlled and closely monitored injection of perchloroethylene (PCE), a typical DNAPL, was undertaken in the Borden sand aquifer northwest of Toronto in 1991 at the Canadian Forces Base Borden. Redman (1992) provides a detailed description of the controlled injection into the 9-m x 9-m x 3.3-m deep Borden cell, which was isolated on four sides by double steel sheet piling and underlain by a particle-sized clay aquitard (Bauman 1989). The natural aquifer consists of fine to medium grained sand with silt lenses, deposited in a progradational foreshore environment (Bohla 1986). The cell was considered water-saturated by artificially maintaining the water table at $15 \mathrm{~cm}$ beneath the smoothed ground surface. Approximately 770 liters of PCE were injected under constant head at $60 \mathrm{~cm}$ below ground surface over a 70-hour period.

\section{Geophysical Data}

Many technical papers and theses have been published regarding the extensive geophysical monitoring of the Borden injection (a few are Olhoeft 1992; Sander and others 1992; Schneider and Greenhouse 1992; Redman 1992; Brewster and others 1992; Brewster and Annan 1994; Sander 1994; Brewster and others 1995). Figure 2 (after Brewster and others 1995) illustrates the locations of each geophysical method employed throughout the cell. Access tubes AT-1 through AT-8 (equispaced on a circle of radius $3 \mathrm{~m}$ from the central injection point) and AT-9 (located $1 \mathrm{~m}$ from the injection) were used for neutron, gamma ray, density, and induction logging (Schneider and Greenhouse 1992), with AT-1 through AT-8 additionally used for hole-to-hole borehole radar measurements (Sander and others 1992; Olhoeft 1992). In situ resistivity probes were employed using access through R-1 and R-2 (Schneider and Greenhouse 1992) and borehole time domain reflectometry (TDR) probes were employed using access through T-1 and T-2 (Redman and Annan 1992; Brewster and others 1992). Surface resistivity (Schneider and Greenhouse 1992) and multiple-frequency surface GPR (Brewster and others 1995; Sander and others 1992; Sander 1994; Sander and Olhoeft 1994) were also employed at the site, with the grid of GPR survey lines shown in Figure 2. The ability of electrical geophysical methods to detect zones of DNAPL results from the distinctly contrasting electrical properties of the DNAPL from the groundwater displaced in the pore spaces (Brewster and others 1992; Olhoeft 1992; Annan and others 1991; Redman and others 1991; Redman and Annan 1992). Additionally, neutron logging was expected to respond to the low neutron porosity associated with PCE compared to water; density and gamma ray logging were expected to respond to the greater density of PCE compared to water (Schneider and Greenhouse 1992). 


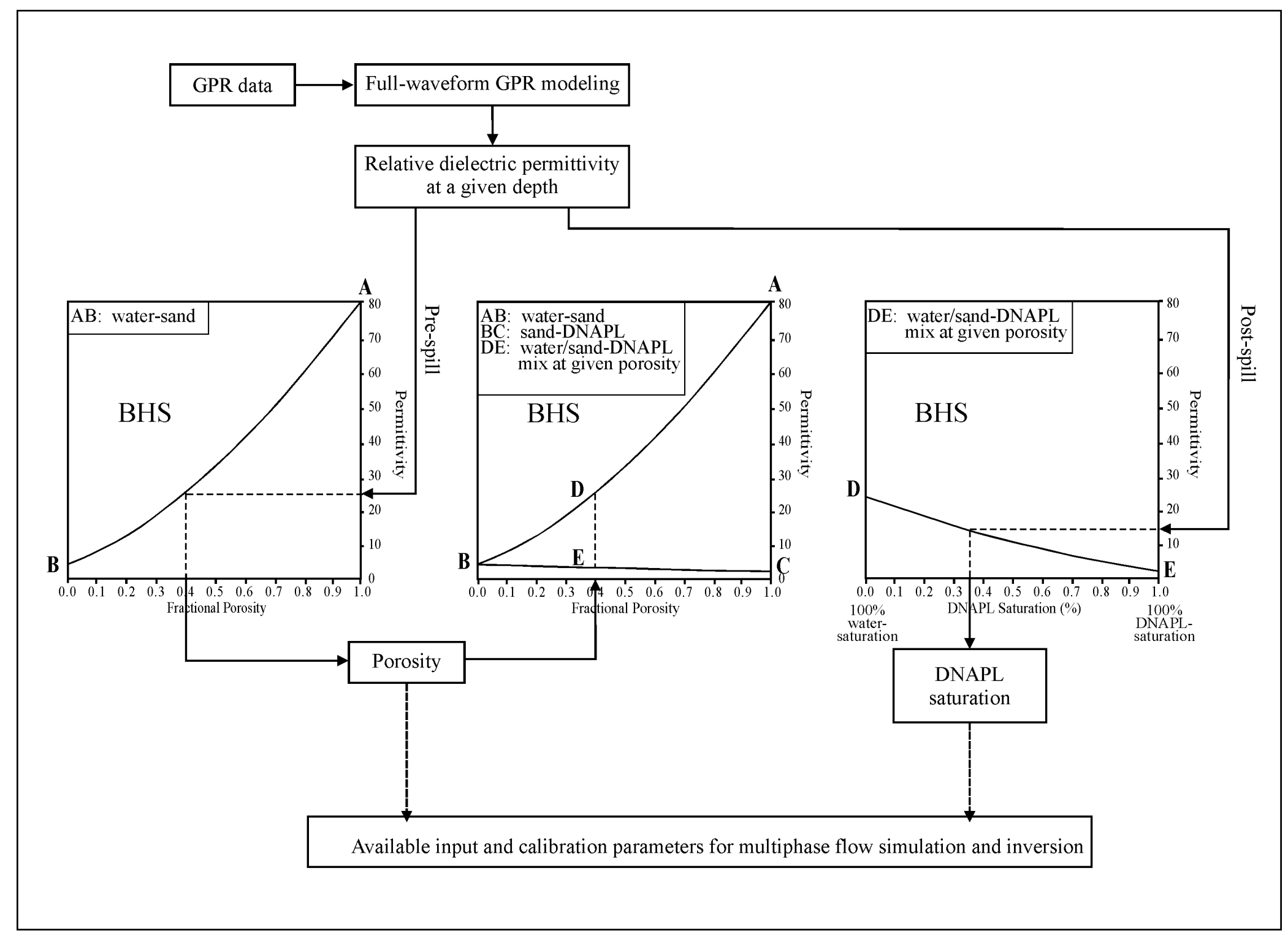

Fig. 1. Flowchart describing the process of determining subsurface porosity and DNAPL saturation from the GPR data using the BruggemanHanai-Sen (BHS) mixing formula (Bruggeman 1935; Hanai 1968; Sen and others 1981) and application of results for starting model and calibration parameters for multiphase flow simulation and inversion. 


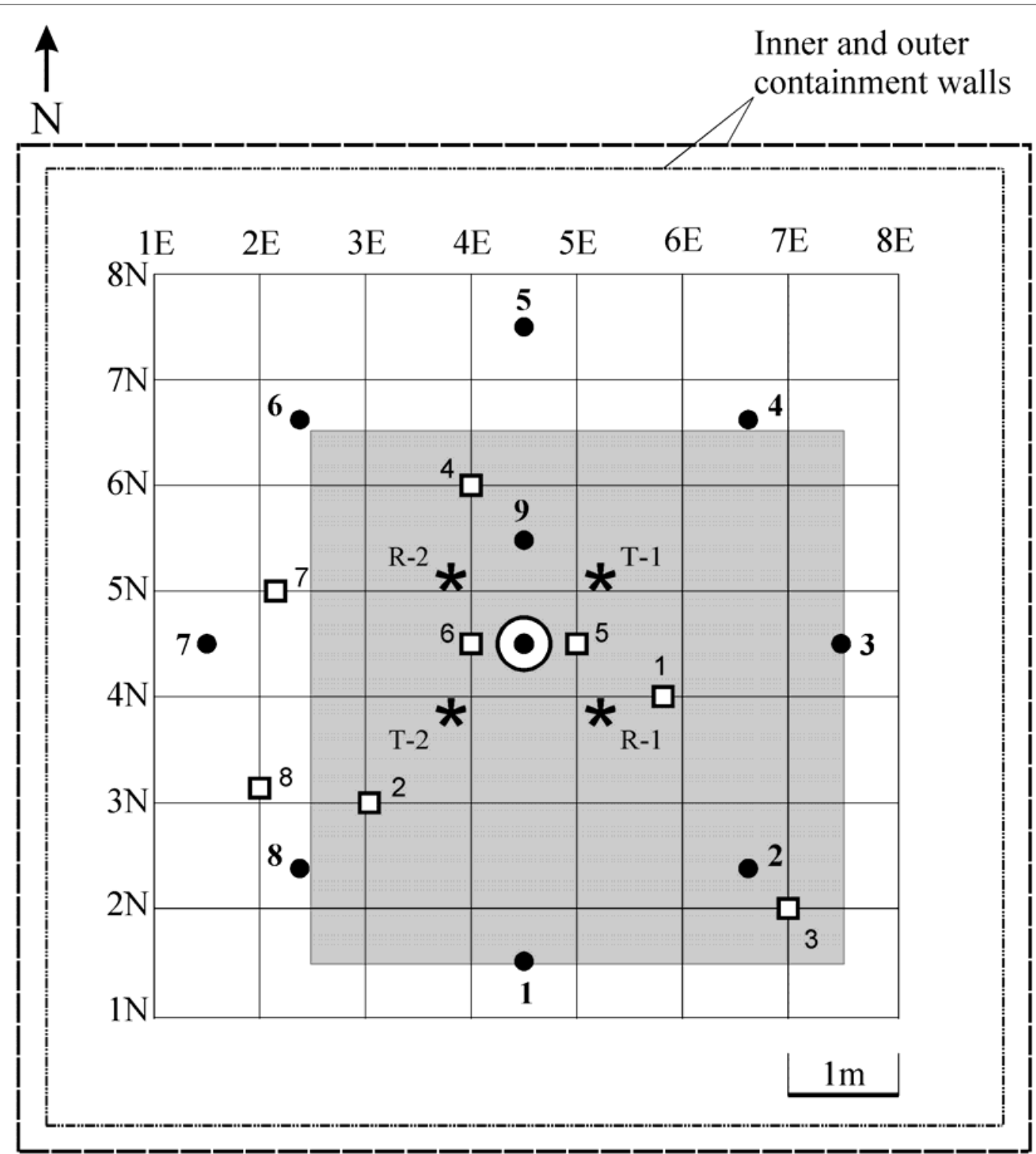

(-) Injection Point

Model Domain

- Access Tubes (1 through 9)

口 Post-injection Cores (1 through 8)

* In Situ Resistivity (R) and TDR (T) Probes

- GPR Survey Lines (1E to $8 \mathrm{E}, 1 \mathrm{~N}$ to $8 \mathrm{~N}$ )

Fig. 2. Plan view map of 9-m x 9-m experimental Borden cell showing layout of instrumentation (after Brewster and others, 1995). Shaded region indicates GPR and multiphase flow model domain. 
Grids of 500-MHz surface ground penetrating radar (GPR) data were among the geophysical data acquired by the U. S. Geological Survey in conjunction with the University of Waterloo during the PCE injection (Sander and Olhoeft 1994) and are used to interpret pre-injection porosity and subsequent DNAPL saturations presented here. Sander and others (1992) describe the 500-MHz data acquisition using a GSSI SIR-7 radar system over a 340-hour post-injection period. For each suite of data, there were a total of 16 radar survey lines, with 8 lines trending north to south (1E to $8 \mathrm{E}$ ) spaced $1 \mathrm{~m}$ from each other, and 8 lines trending west to east ( $1 \mathrm{~N}$ to $8 \mathrm{~N}$ ) spaced $1 \mathrm{~m}$ from each other (Figure 2).

Also available are a series of pre-injection cores from the eight access tubes and cores obtained at 1000 hours post-injection from locations CP-1 through CP-8 (Figure 2). Ground truth for the various geophysical data was provided from the post-injection cores. Cores $\mathrm{CP}-1$ through $\mathrm{CP}-4$ were evaluated in $5-\mathrm{cm}$ intervals and cores CP-5 through CP-8 were evaluated in $8-\mathrm{cm}$ intervals for pre-injection porosity and 1000 hour post-injection PCE saturation distribution (Brewster and others, 1995). Pre-injection porosity was determined from measures of core volume, dry sample weight, and grain density; postinjection PCE saturation was determined from extraction of core PCE into methanol and inferring saturation from spectrophotometer and gas chromatography measurements of the methanol. Information from each of the interpreted geophysical data sets shown in Figure 2 was later used in constraining the GPR modeling parameters of the 500-MHz GPR data presented here.

\section{0-MHz GPR BORDEN DATA}

Qualitative information on the migration behavior of PCE in the Borden cell may be ascertained from visual inspection of the GPR profiles over time and is provided by Sander and others (1992), Sander (1994), Brewster and others (1995), and Greenhouse and others (1993). Comparison of pre- to postinjection images and traces indicates which features are pre-existent and which are due to mobilization or pooling of DNAPL. To facilitate this comparison, GPR data were regularized to common spatial, time, and gain scales. Data were topographically corrected using available survey data (Olhoeft 1998) and accurately positioned using cubic spline interpolation between 1-m marks in the raw data. The data were then converted to a standard format before binning and smoothing. A bin increment of $1 \mathrm{~cm}$ with a bin width of $10 \mathrm{~cm}$ was applied to the raw data of originally 1-2 traces/cm density resulting in output files of one trace per centimeter (i.e., no new data was created in the process). Binned data were de-wowed using a $150-\mathrm{MHz}$ low-cut Hanning-window filter. Each file was then zero-time shifted by first removing the field range gain, positioning the zero sample at the top of each trace, then applying a common range gain across all parcels of data at all elapsed times.

The GPR acquisition grid over the Borden cell is shown in Figure 2 and a time-series image of the regularized data along line 4E is shown in Figure 3 ( 0,14 , and 22 hours post-injection). The shaded area of Figure 2 defines the surface domain of the multiphase flow model and the outlined area of Figure 3 defines the vertical domain. Line 4E illustrates that accumulation of PCE appears as a bright reflector amplified in the GPR record over time. The most prevalent DNAPL feature within the Borden cell is an apparently continuous spreading zone at approximately 30-40 nanoseconds (ns) two-way travel time (Figure 3), which is equivalent to approximately $1-\mathrm{m}$ depth assuming an average relative dielectric permittivity of 25 for the cell (Olhoeft 1992). This zone bows slightly upward near the injection and follows an inferred channel to the south of the injection, trending nearly parallel to the southern boundary of the cell and dipping toward the eastern boundary. The upward bowing is most likely due to the rate of injection exceeding the rate of horizontal flow, rather than due to a pre-injection geometry.

Aside from the bright reflection horizon indicating the presence of PCE, there are several other characteristics of the GPR data not indicative of incoming PCE. These include the diagonal reflections off the sheet pile walls, the reflection off a confirmed till layer seen below $80 \mathrm{~ns}$, the direct first-arrival energy recorded just after time zero, and various pre-existing layers that do not fill with PCE (Figure 3). These details do not change with time and detract from visual interpretation. One way to enhance DNAPL features is to difference the data along each trace for two profiles in time. Difference images were used only to qualitatively enhance our subsurface view of DNAPL, delineating relevant features to be 

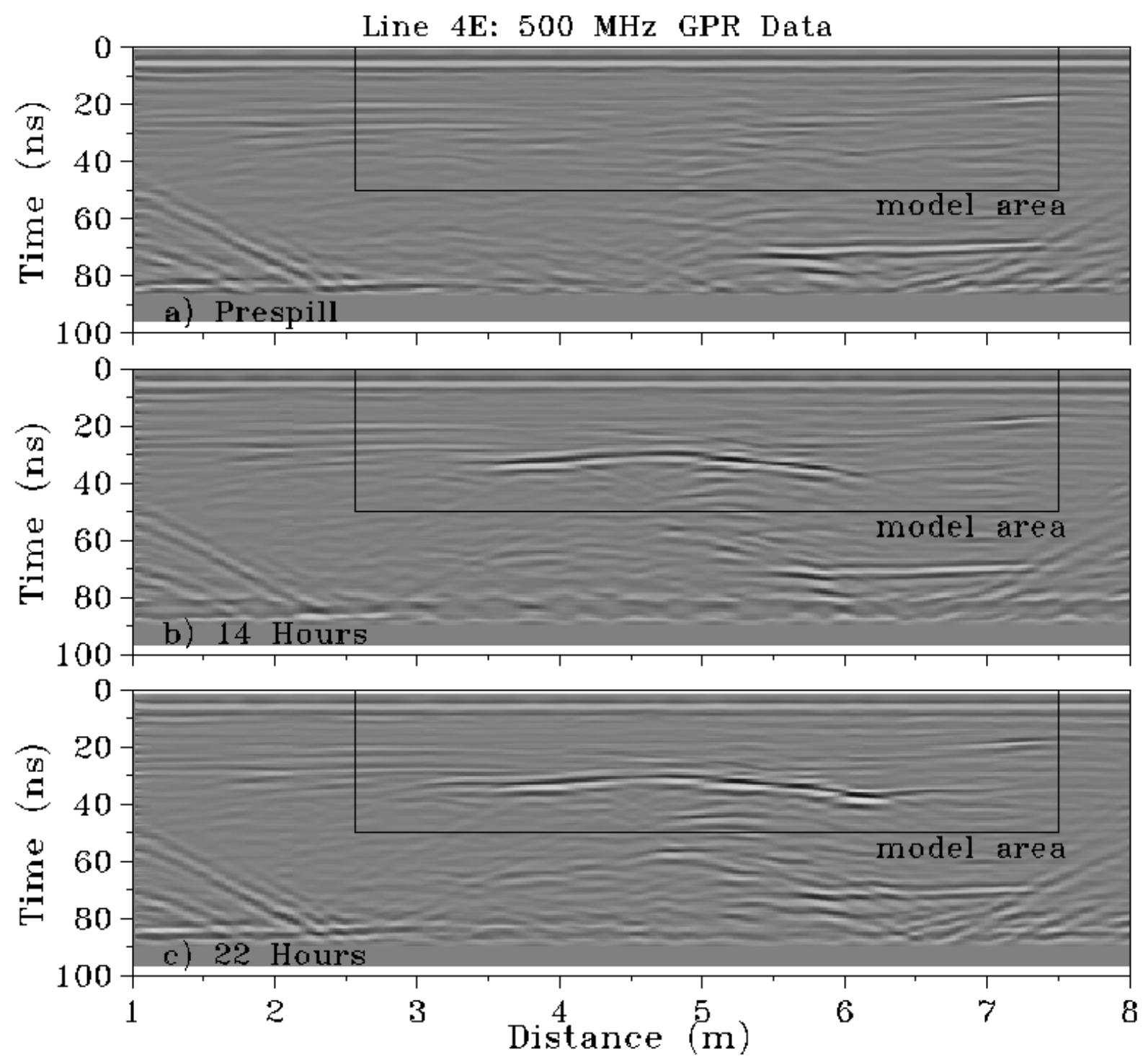

Fig. 3. Regularized $500 \mathrm{MHz}$ GPR time series of line 4E: pre-injection, 14, and 22 hours post-injection. Outlined model area indicates GPR and multiphase flow model domain. DNAPL is implied by increased amplitudes over time, as seen at approximately $30 \mathrm{~ns}$ between 3.5 and $6.5 \mathrm{~m}$. DNAPL can be seen entering an inferred channel located at $40 \mathrm{~ns}$ two-way travel time between 6.0 and $6.3 \mathrm{~m}$ by 22 hours post-injection. The bright reflection at approximately $70 \mathrm{~ns}$ two-way travel time between $3 \mathrm{~N}$ and $2 \mathrm{~N}$ is a confirmed till layer, rather than DNAPL accumulation, as its character does not change appreciably with time. Diagonal reflections are airwave arrivals from the above-ground portion of the sheet-pile containment walls. The reflector at $80 \mathrm{~ns}$ two-way travel time extending across the profile is another confirmed till layer. 
interpreted in GPR modeling. Results of difference images, however, cannot be analyzed on a wavelet scale to quantify DNAPL saturation due to slight positioning uncertainties.

\section{INTERACTIVE FULL-WAVEFORM GPR MODELING}

\section{Background}

For quantitative information on porosity, DNAPL accumulation thickness, and fluid saturation, interactive full-waveform GPR modeling was applied to regularized raw waveform data. Sander (1994) describes initial attempts at interactive forward GPR modeling, and provides a framework for the research continued by Sneddon and others (2000) and developed further here. The one-dimensional (1-D) fullwaveform GPR modeling software used in this research is a module of GRORADAR ${ }^{\mathrm{TM}}$ version 8.99 (Olhoeft 1998), which is based upon GPRMODV2 by Powers and Olhoeft (1995). Detailed description and consideration of the theoretical development and calculation of the GPR forward model is provided by Powers (1995). This software requires input of a layered geological model defined by thickness and electromagnetic properties of complex dielectric permittivity, electrical conductivity, and complex magnetic permeability. Given an earth model, the program computes the associated GPR response by calculating the character of the transmitted and reflected waves as the pulse is propagated through a geological model of flat, horizontal layers of specified thickness and associated electromagnetic properties. Solutions are nonunique, but may be constrained by the user with prior knowledge of the medium and/or subsurface geometry.

\section{Model Parameters}

Table 1 summarizes parameters used in the GPR modeling that were based on prior information from previous research of the Borden cell. Information summarized in Table 1 was used as direct input to the interactive full-waveform GPR models and in subsequent calculations of pre-injection porosity and post-injection DNAPL saturation. GPR models were further constrained by previous studies of DNAPL pooling history available from multiple-frequency surface GPR results (Brewster and others 1995; Sander and others 1992; Sander 1994), surface and borehole resistivity (Schneider and Greenhouse 1992), borehole time domain reflectometry (Brewster and others 1992) at location TDR-1 (Figure 2), and neutron logging (Schneider and Greenhouse 1992) at location AT-8 (Figure 2). Hole-to-hole radar data available from Olhoeft (1998) were also evaluated for use in this study to constrain pooling history. Figure 2 shows which available data lie within the GPR model domain.

Earth properties are interpreted from the field data by interactively changing the geological model and associated electromagnetic properties until the computed GPR response to this model matches the field data trace. Because equivalent responses may result from a variety of input models, the interpreter must use available information to create a model that is consistent with the likely geology and material properties. In the Borden cell, time lapse images (Figure 3) suggest a geologic model of material property and thickness variation where visible pooling of PCE is observed between approximately 0.70 and $1.17 \mathrm{~m}$ (Table 2).

As a result of the distinct contrast between the relative dielectric permittivities and electrical conductivities of water and PCE, the bulk electrical properties of the water-saturated Borden aquifer will be altered by PCE injection (Lucius and others 1992). As the more resistive and lower dielectric permittivity PCE displaces water in the pore spaces, the bulk conductivity and relative dielectric permittivity of the cell are also expected to decrease (Table 1); no change is expected in the magnetic properties. To approximate this effect in the interpreted post-injection GPR models, electrical conductivity values were made to decrease incrementally in a range of 14.0 to $0.25 \mathrm{mS} / \mathrm{m}$ as the modeled bulk relative dielectric permittivity decreases from 25 to 9 . 
Table 1. Measured and assumed parameters used in GPR modeling

\begin{tabular}{|c|c|c|}
\hline PARAMETER & VALUE & REFERENCE \\
\hline \multicolumn{3}{|l|}{ Dry Borden Sand: } \\
\hline Relative dielectric permittivity & 4.5 & Sander and others 1992 \\
\hline Conductivity $(\mathrm{mS} / \mathrm{m})$ & $<1$ & Sander 1994 \\
\hline \multicolumn{3}{|l|}{ Borden Water: } \\
\hline Relative dielectric permittivity & 80 & Olhoeft 1992 \\
\hline Conductivity $(\mathrm{mS} / \mathrm{m})$ & 50 & Redman and others 1991 \\
\hline \multicolumn{3}{|l|}{ Water-saturated Borden Cell: } \\
\hline Average relative dielectric permittivity & 25 & Olhoeft 1992 \\
\hline Modeled relative dielectric permittivity & $19-27$ & Current research \\
\hline Conductivity $(\mathrm{mS} / \mathrm{m})$ & 14 & Schneider and Greenhouse 1992 \\
\hline Average porosity (fractional \%) & 40 & Brewster and others 1995 \\
\hline Detailed porosity (fractional \%) & $31-43$ & Current research \\
\hline \multicolumn{3}{|l|}{ PCE: } \\
\hline Relative dielectric permittivity & 2.3 & Lucius and others 1992 \\
\hline Conductivity $(\mathrm{mS} / \mathrm{m})$ & $<1$ & Redman 1992 \\
\hline \multicolumn{3}{|l|}{ Water-saturated Borden Sand with PCE: } \\
\hline Relative dielectric permittivity & $3.4-29.7$ & Redman 1992 \\
\hline Conductivity $(\mathrm{mS} / \mathrm{m})$ & $0-14.5$ & Redman 1992 \\
\hline \multicolumn{3}{|l|}{ Layering } \\
\hline $\begin{array}{l}\text { Thin, low permeability stringers } \\
\text { controlling PCE accumulation }\end{array}$ & $\begin{array}{l}\text { cm-scale } \\
\text { vertically }\end{array}$ & $\begin{array}{l}\text { Schneider and Greenhouse } 1992 \\
\text { (borehole resistivity; gamma } \\
\text { ray, density, and induction } \\
\text { logging); } \\
\text { Brewster and others } 1992 \\
\text { (borehole TDR); } \\
\text { Olhoeft } 1992 \\
\text { (hole-to-hole borehole radar) } \\
\text { Current research } \\
\text { (visual inspection of cores) }\end{array}$ \\
\hline \multicolumn{3}{|l|}{ Additional Assumptions } \\
\hline Magnetic permeability (real part) & 1 & \multirow{3}{*}{ For all materials } \\
\hline Magnetic permeability (imaginary) & 0 & \\
\hline Dielectric permittivity (imaginary) & 0 & \\
\hline No frequency dependence & & \\
\hline Horizontal Layering & & \\
\hline
\end{tabular}

Table 2: Conceptual model of pre-injection cell conditions

\begin{tabular}{|c||c||c||c|c|}
\hline Layer & $\begin{array}{c}\text { Dielectric } \\
\text { Permittivity }\end{array}$ & Depth to Bottom (m) & Relative Porosity & $\begin{array}{c}\text { Fractional } \\
\text { Porosity } \\
(\%)\end{array}$ \\
\hline \hline I & 25 & $0.63-1.00$ & Average & 40 \\
\hline II & $19-23$ & $0.70-1.05$ & Less than average & $31-37$ \\
\hline III & $22-27$ & $0.74-1.10$ & Greater than average & $35-41$ \\
\hline IV & $20-23$ & $0.89-1.17$ & Less than average & $33-37$ \\
\hline V & $23-25$ & 2.00 & Average & $37-40$ \\
\hline
\end{tabular}




\section{Assumptions}

The forward modeling program assumes infinitely horizontal layer boundaries of homogeneous, isotropic material in the far-field region of the antenna. The simplified 1-D, flat-layer models will not account for amplitude focusing effects resulting from 2-D or 3-D features with non-horizontal boundaries (such as a channel), nor for out-of-plane reflections (Olhoeft 1994) from the sidewalls, but it does include multiples within a layer. Further assumptions are summarized in Table 1.

In addition, the GPR modeler must assume a starting wavelet. The forward modeling code computes the response of this wavelet originating from the antenna as it interacts with the user-defined geoelectric model of the earth. The true starting wavelet is not known because it is a property of the antenna and its near-field conditions (including ground coupling), properties that vary within each GPR profile. In this research, a Ricker wavelet with a center frequency of $273 \mathrm{MHz}$ (approximating the output of a $500-\mathrm{MHz}$ antenna after loading due to ground coupling) was used as the starting pulse for the modeling. For the particular $500-\mathrm{MHz}$ antenna used in data acquisition at Borden, the Ricker wavelet is expected to resemble the true starting pulse (Duke 1990), with polarity of the wavelet dependent on its reflection behavior through the material half-space. Though it was not the intention of this research to characterize the $500-\mathrm{MHz}$ antenna used, similar models calculated with the varying starting wavelets (Figure 4) are presented in Figure 5 to demonstrate the effects of the wavelet selection on modeling results. For the single trace modeled with the modified airwave measured by Duke (1990), a geologically reasonable alternative model is produced. This wavelet has not yet been used for an extensive remodeling of the cell, but models shown in Figure 5 provide an estimate of model uncertainty resulting from starting-wavelet uncertainty. A significant result of varying the starting wavelet is seen in the decreased number of thin layers necessary to create a match to the field trace using the modified air wavelet. To match asymmetry in the data, constructive and destructive interference is simulated with the introduction of thin layers whereas the modified air wavelet has an inherent asymmetry.

\section{Interpretation}

While the true geologic layering within the cell is complex and locally variable, a GPR model that matches the field data is created using the simplest geology reasonable. In an effort to elucidate the actual zone of PCE accumulation without modeling more layers than necessary, each trace to be modeled was first windowed according to
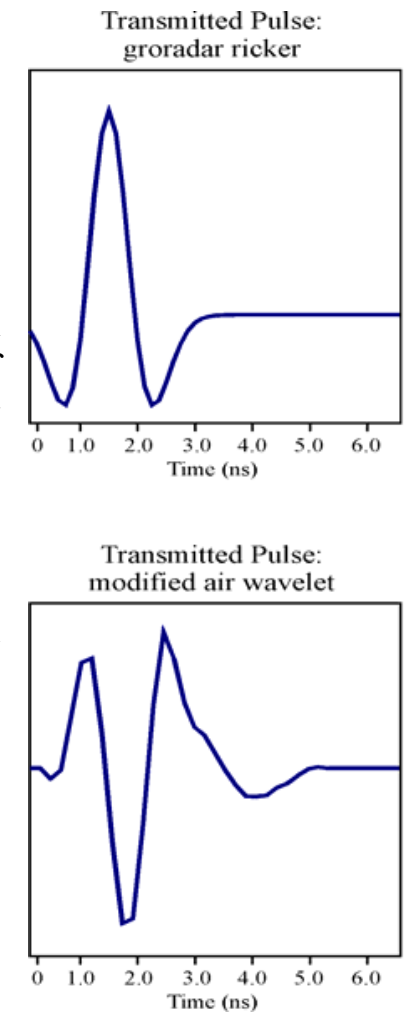

Fig. 4. Comparison of the Ricker starting wavelet used in GRORADAR ${ }^{\mathrm{TM}}$ version 8.99 (Olhoeft 1999) to the modified airwave (after Duke 1990). Polarity of the wavelet is dependent on its reflection behavior through a material halfspace. amplitude changes evident in the first 22 hours post-injection. Figure 6 shows an example of the windowing process for a field trace located at the intersection of lines $4 \mathrm{E}$ and $3 \mathrm{~N}$ at times 0,14 , and 22 hours post-injection. The field traces do not appreciably differ for times preceding $30 \mathrm{~ns}$ two-way travel time and variations noted at times later than $75 \mathrm{~ns}$ are due mainly to radio-frequency interference (Canadian Forces Base Borden is Canada's main communications base). In the first 22 hours at this location, the main zone of accumulation lies between 32 and $64 \mathrm{~ns}$, with greatest amplitude variation between 32 and $44 \mathrm{~ns}$. The domain of the multiphase flow simulation is defined to a depth of $2.5 \mathrm{~m}$ 


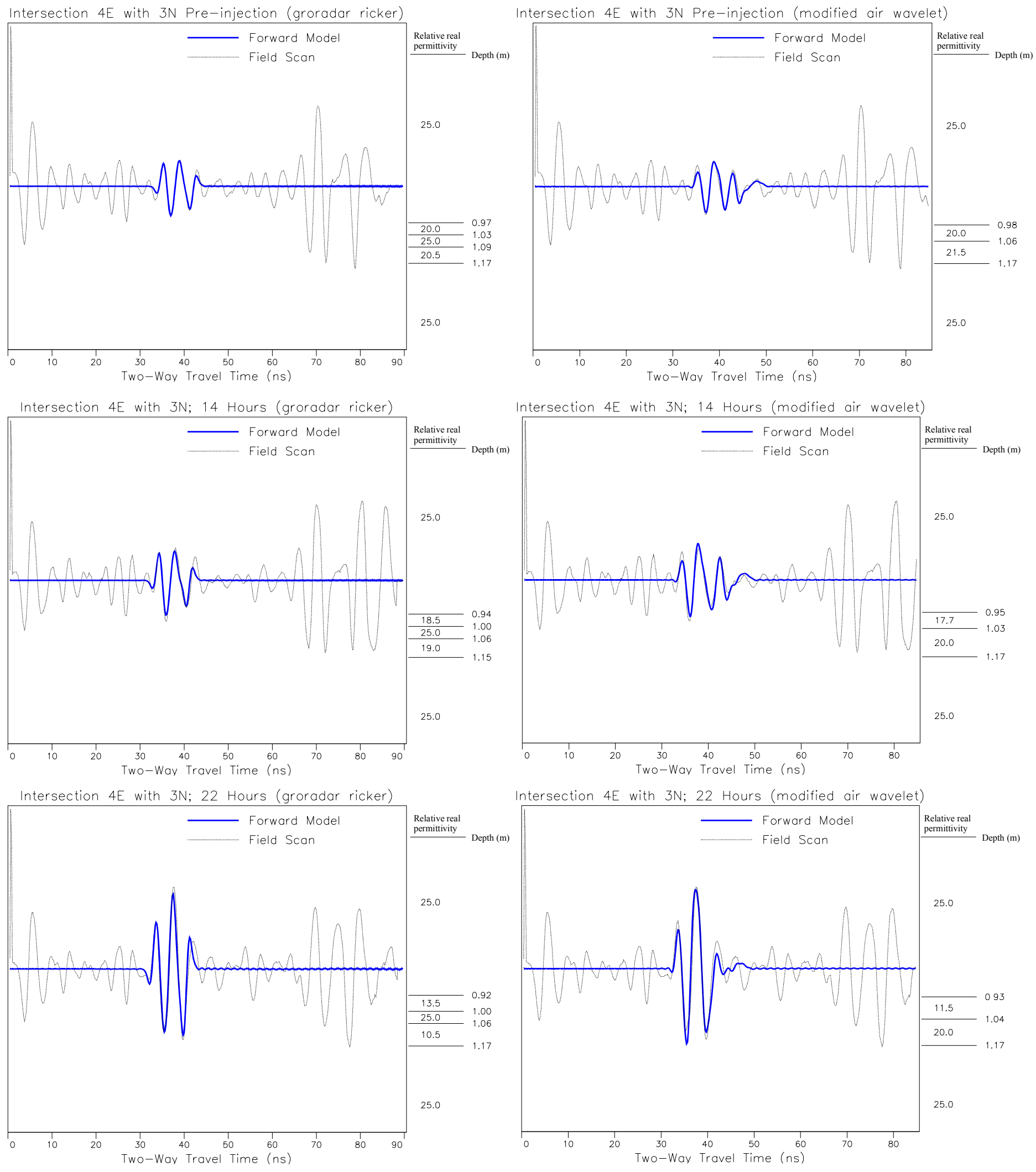

Fig. 5. Comparison of interactive GPR forward modeling results with different starting wavelets. On the left are results from use of a Ricker wavelet. On the right are results from use of a modified airwave (after Duke 1990) measured with the 500-MHz antenna used at Borden. 


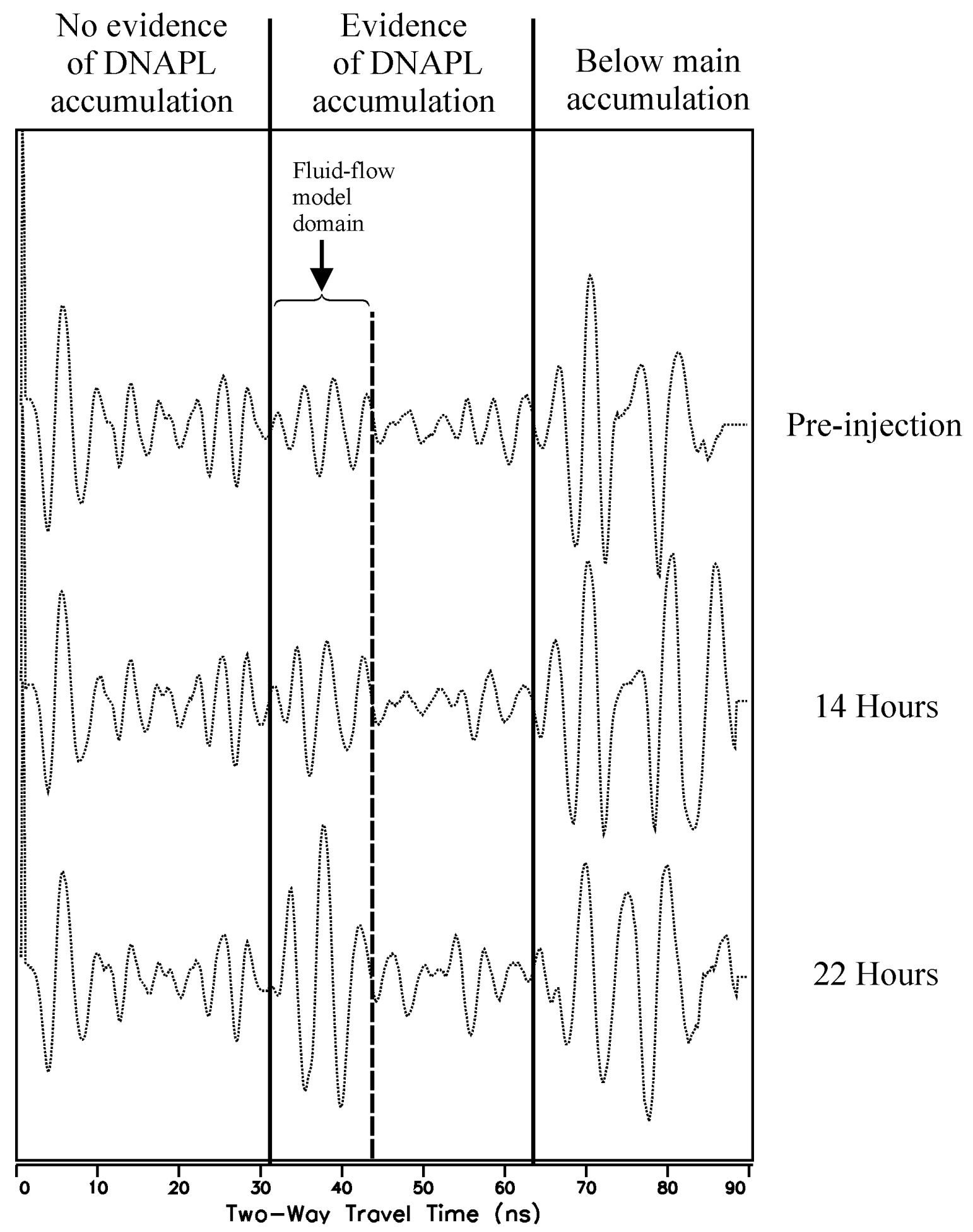

Fig. 6. Demonstration of windowing process using example from field traces at intersection of line $4 \mathrm{E}$ and $3 \mathrm{~N}$ : pre-injection, 14 hours, and 22 hours post-injection. Little or no change in character of the trace before approximately $32 \mathrm{~ns}$ indicates little or no DNAPL accumulation in that zone. Clear DNAPL accumulation is evidenced in the model window by increases in amplitude and phase shifts. Radio-frequency interference at times later than $75 \mathrm{~ns}$ precludes modeling in that zone. 
(corresponding to approximately $42 \mathrm{~ns}$ assuming an average radar velocity of $0.06 \mathrm{~m} / \mathrm{ns}$ ), though there is evidence of another DNAPL accumulation around $55 \mathrm{~ns}$.

The time-lapse images in Figure 3 suggest that a change in geology at approximately 30 to $45 \mathrm{~ns}$ is the main control on PCE flow in the first 22 hours post-injection. The 1-D field scans at the intersection of line $4 \mathrm{E}$ and $3 \mathrm{~N}$ shown in Figure 6 also indicate that the largest changes occur within this same time window corresponding to depths between approximately 0.9 and $1.4 \mathrm{~m}$ (assuming an average cell relative dielectric permittivity of 25 ). Core data illustrate the complexity of the geologic layering on a centimeter scale, but confirm a broad change occurring at depths between approximately 0.6 and $1.5 \mathrm{~m}$ (Figure 7). The challenge in modeling GPR field data for use in multiphase flow simulation is creating a simple geologic model that is complex enough to represent the main controls on PCE flow, which in this case appear to be most significant in the 30 to $45 \mathrm{~ns}$ time window.

Within the selected time window, the GPR modeler must prioritize matching criteria regarding phase and amplitude. In modeling presented here, greater priority was assigned to matching phase of peaks, troughs, and zero crossings than was assigned to matching amplitude. At $500-\mathrm{MHz}$ frequency in a medium of average dielectric permittivity 25 , decreases in relative dielectric permittivity and increases in conductivity from PCE infiltration affect GPR velocity (evident as phase and zero crossing) more than they affect GPR attenuation (evident as amplitude variation) within the assumptions of the forward modeling program.

As the interpreter models each trace along a GPR profile, care is taken to maintain geologic consistency. The 3-D geological model resulting from consideration of all the independent, 1-D models created on a $0.5-\mathrm{m}$ grid over the test cell approximates the subsurface. This 3-D model is related to the true subsurface only in that the 1-D flat-layer computed responses to the model, given the estimated and idealized starting pulse shape, match the acquired field data, over a limited window of two-way travel time, at every $0.5-\mathrm{m}$ grid point. Any additional information used to constrain the geological model, including measured values of material properties and geological understanding of the depositional environment, increases the likelihood that the model is an adequate approximation of the true subsurface.

Though a three-layer model adequately described the portion of the cell modeled by Sander

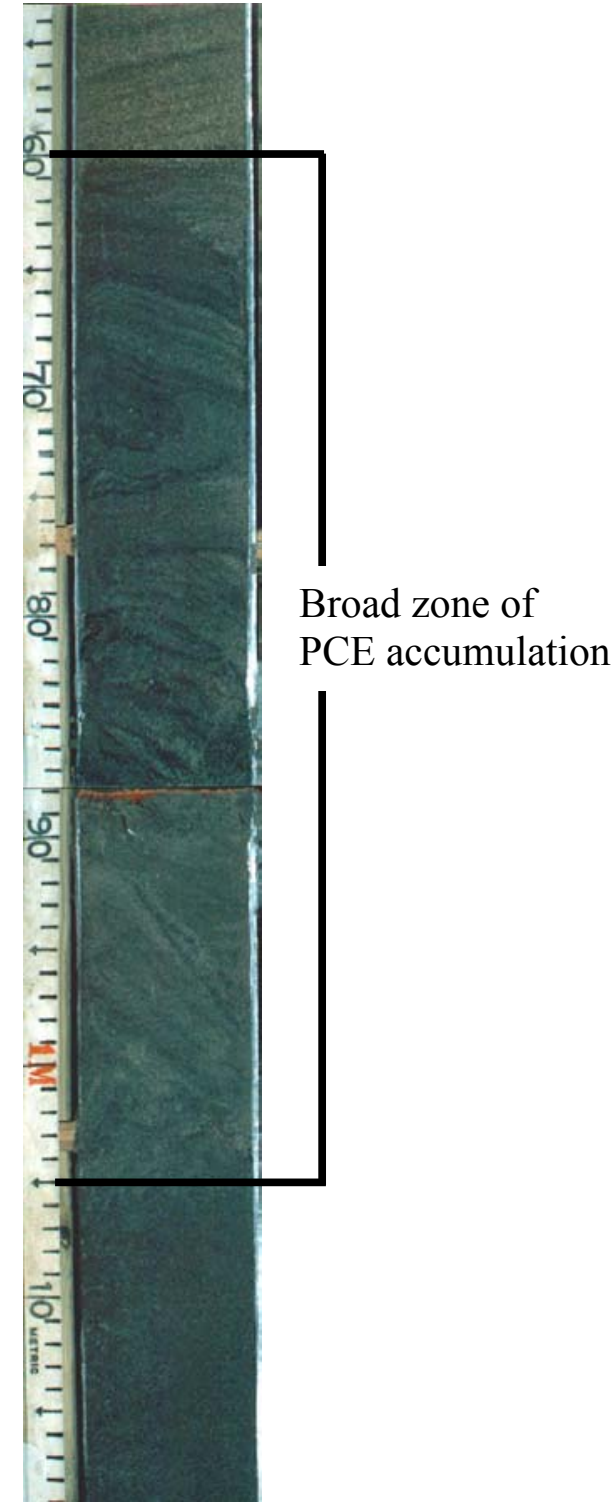

Fig. 7. Pre-injection core from access tube AT-8 illustrating cm-scale complexity of geologic layering with more broad variation between approximately 0.6 to $1.5-\mathrm{m}$ depth where PCE tended to accumulate in the Borden cell. (Feature at $0.88 \mathrm{~m}$ is a break in the core.) (1994), further modeling throughout the cell indicated the necessity for at least a five-layer conceptual model for a good match with broad consistency. Figure 8 shows an example of constructing a five-layer model using a top down approach and adding a layer at a time for the field trace windowed in Figure 6. 


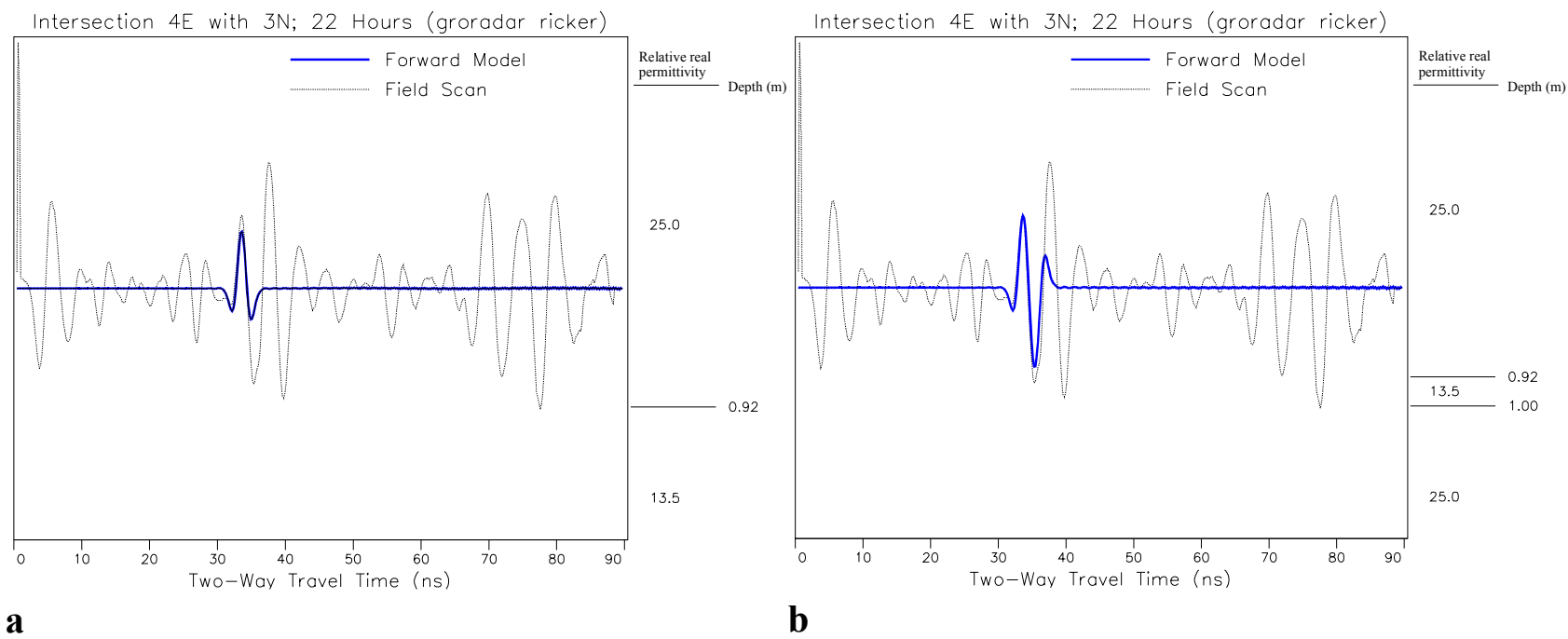

$\mathbf{a}$

\section{b}

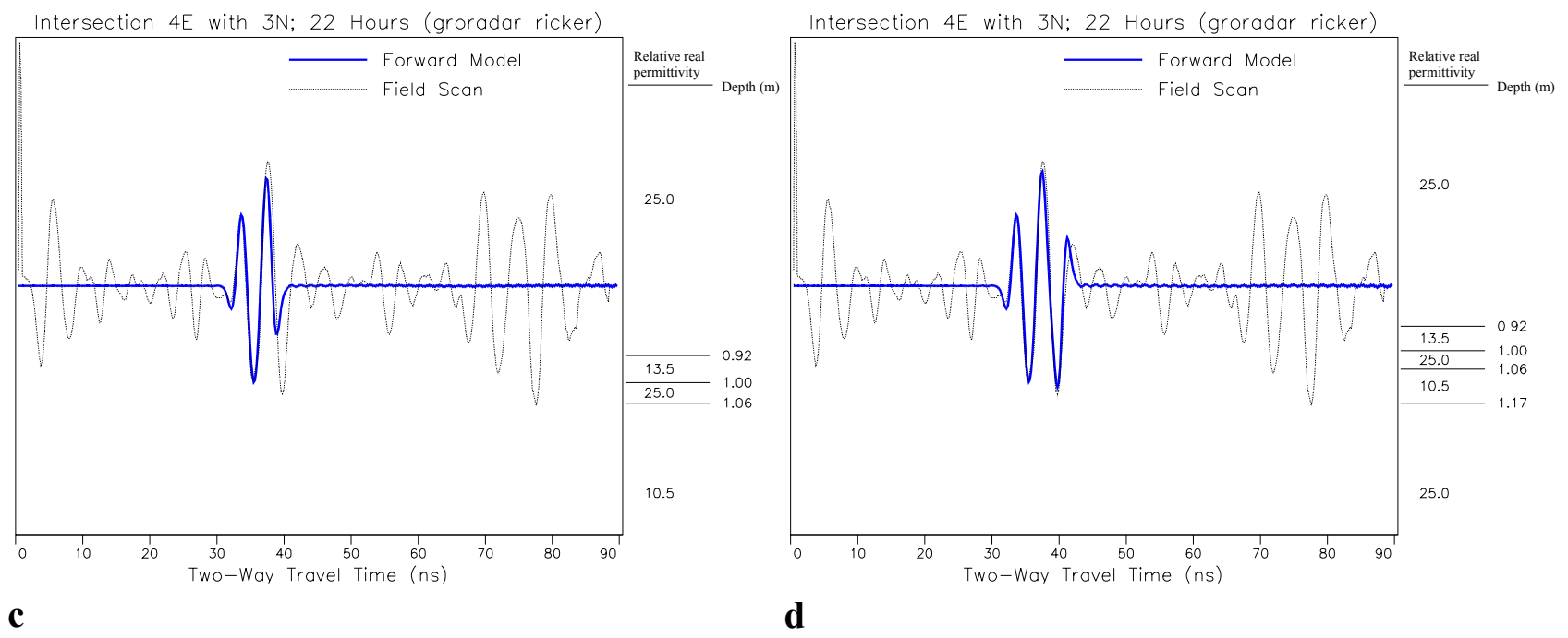

Fig. 8. Example of building a model from two layers (7a) to three layers (7b) to four layers $(7 \mathrm{c})$ to five layers (7d) for the point along $4 \mathrm{E}$ intersecting with lines $3 \mathrm{~N}$ at 22 hours post-injection. Depth of modeled layers is determined from the windowing process shown in Figure 5.

As expected, the amplitude of the field trace increases with the introduction of PCE. The zone preceding $30 \mathrm{~ns}$ is held constant at a relative dielectric permittivity of 25 , the background for the cell, based on the assumption that complex cm-scale layering and material property variation can be averaged as a single m-scale layer above and below the main zone of PCE accumulation. Further layers may also be indicated in the zone after $45 \mathrm{~ns}$, but were not modeled at this time and were assumed to remain constant at an average relative permittivity of 25 within the first 22 hours. Using a Ricker starting wavelet, a minimum of five layers is needed to reasonably model the main zone of accumulation.

The GPR model of dielectric permittivity versus location, depth, and time, was determined for a $5-\mathrm{m} \times 5-\mathrm{m} \times 2-\mathrm{m}$ subvolume of the test cell with traces modeled at a spacing of $0.5 \mathrm{~m}$. Figure 9 shows these interpolated models for the pre-injection condition, 14 hours post-injection and 22 hours postinjection. Pre- and post-injection dielectric permittivity values may then be converted to pre-injection porosity and post-injection PCE saturation values as described below. 
Pre-injection
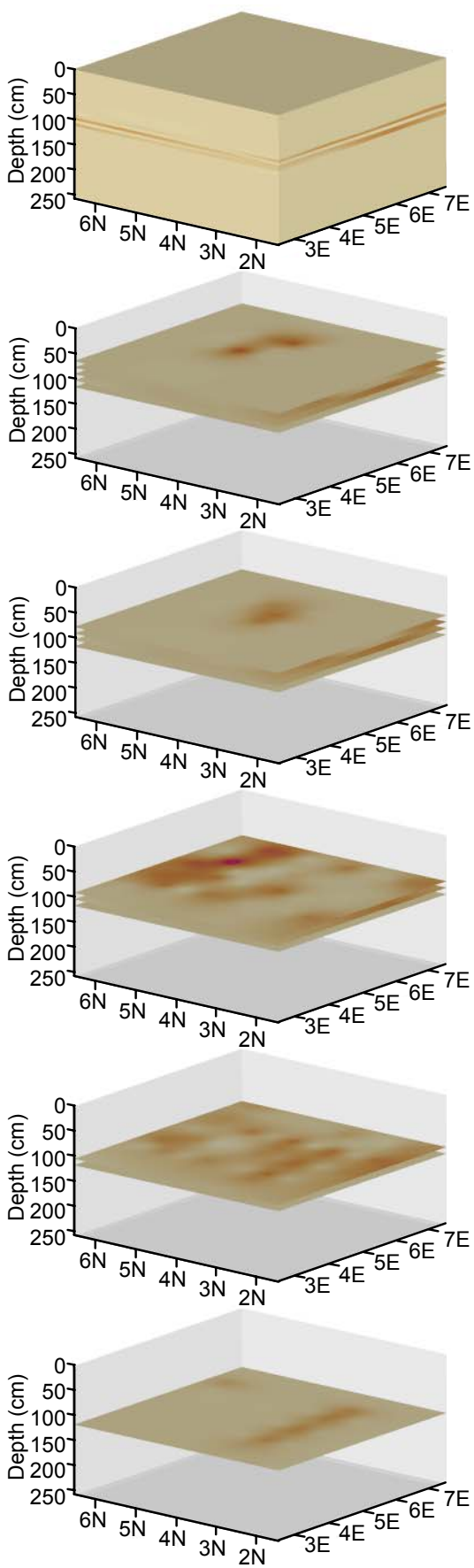

14 hours
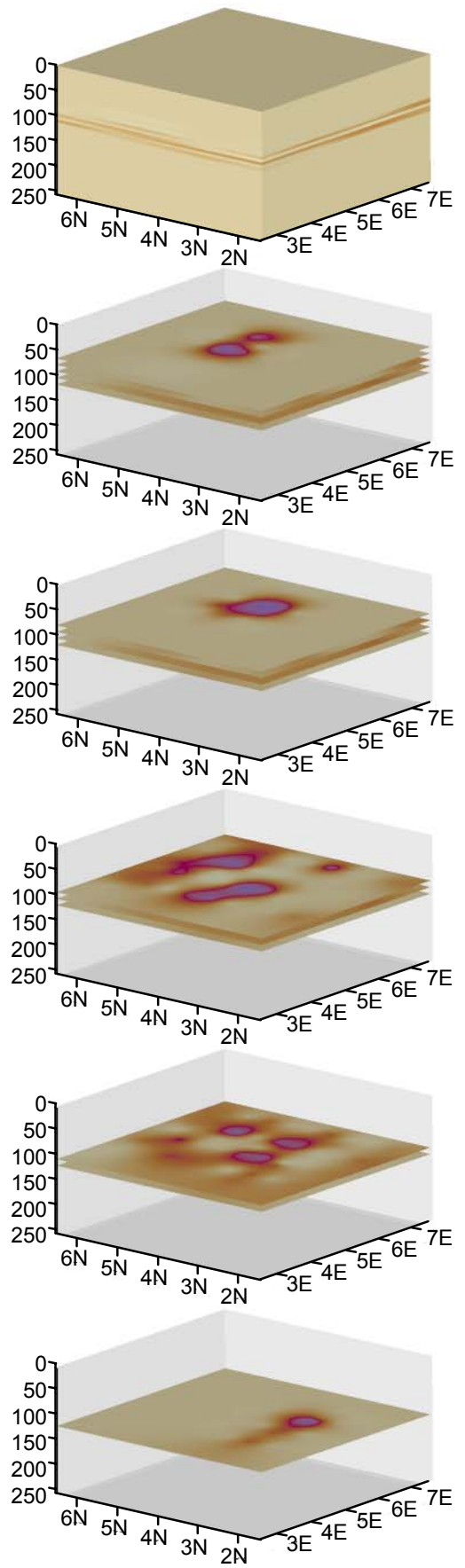

22 hours
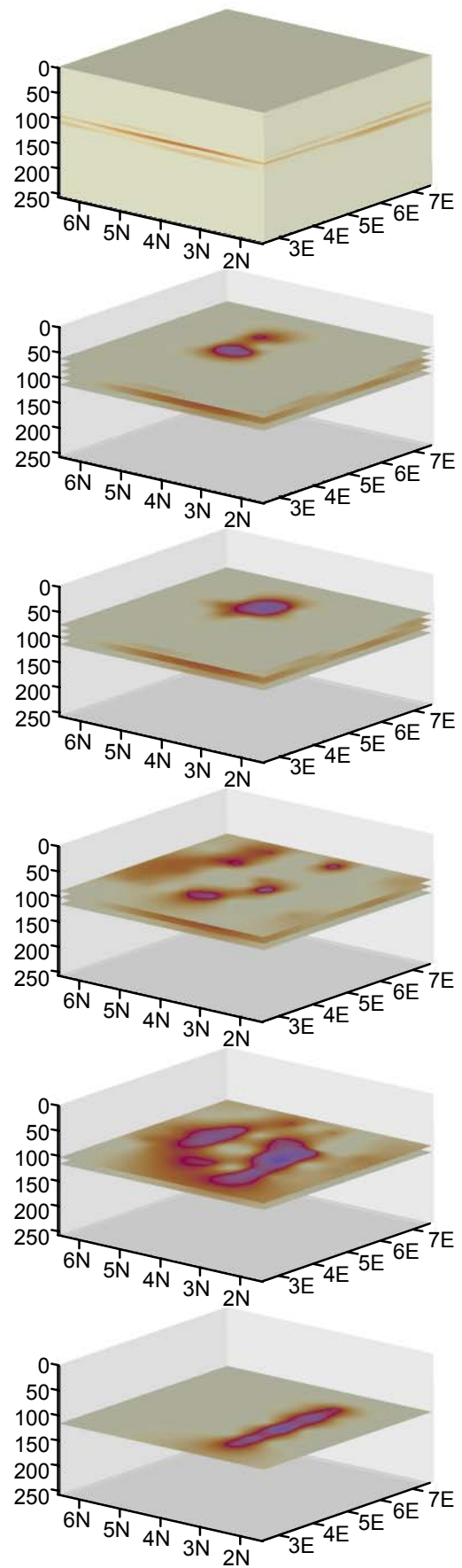

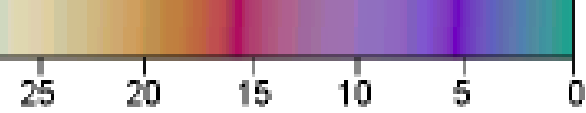

Relative Dielectric

Fig. 9. The three columns show sliced views of the same subvolume of the Borden cell as DNAPL was injected. The color scale represents relative dielectric permittivity variations determined from interactive forward modeling of the GPR data. The column on the left shows the pre-injection condition, where all changes are due to variations in porosity. The center column is modeled from GPR data acquired at 14 hours, and the right column is modeled from data acquired at 22 hours. 


\section{DETERMINING POROSITY AND DNAPL SATURATION VALUES}

The relationship of porosity to the complex dielectric permittivity of two materials and their mixture may be described by the Bruggeman-Hanai-Sen (BHS) mixing formula:

$$
\Phi=\frac{\left(\varepsilon_{\text {matrix }}^{*}-\varepsilon_{\text {comp }}^{*}\right)\left(\varepsilon_{\text {fluid }}^{*} / \varepsilon_{\text {comp }}^{*}\right)^{C}}{\left(\varepsilon_{\text {matrix }}^{*}-\varepsilon_{\text {fluid }}^{*}\right)}
$$

where:

$$
\begin{array}{ll}
\Phi & =\text { fractional porosity } \\
\varepsilon^{*}{ }_{\text {matrix }} & =\text { complex relative dielectric permittivity of the matrix } \\
\varepsilon^{*} \text { fluid } & =\text { complex relative dielectric permittivity of the fluid } \\
\varepsilon^{*} \text { comp } & =\text { complex relative dielectric permittivity of the composite mixture } \\
\mathrm{C} & =\text { shape factor ( } 1 / 3 \text { for spherical grains). }
\end{array}
$$

This formula is an effective-medium-theory mixing method, confirmed for use in this application by Kutrubes (1986). Other mixing methods are often used, including empirically based formulas (Topp and others 1980), and simple volumetric averaging methods (Sihvola 1999). In this case, the BHS formula is used because it can be iterated to estimate values of DNAPL saturation in multiphase mixtures of matrix, water, and DNAPL (Sneddon and others, 2000). The BHS is a volumetric mixing formula describing a physical mixture assuming no interaction between the matrix and the fluid and no scattering (e.g., long wavelength compared to pore and particle sizes). These assumptions are valid for the quartz silica sand of the Borden aquifer, which does not react with water or PCE. In addition, PCE does not react with water.

The first step in applying the BHS formula to modeled GPR parameters (Figure 1) is to determine the porosity of the pre-injection, water-saturated Borden sand for soil horizons of the cell where variations in the pre-injection radar data are assumed to be due to variations in porosity. If the sand is assumed to be $100 \%$ water saturated, and a relative dielectric permittivity of 25 is associated with the average measured porosity of $40 \%$ for the cell (Table 1), then variations in the relative dielectric permittivity of the preinjection volume, attributed to variations in water content, must be the result of changes in porosity. In this step, $\varepsilon^{*}{ }_{\text {matrix }}$ refers to the relative permittivity (approximately 4.5 [Table 1]) of the dry Borden sand $\left(\varepsilon_{\mathrm{s}}^{*}\right) ; \varepsilon^{*}$ fluid is the relative permittivity (approximately 80 with a conductivity of $50 \mathrm{mS} / \mathrm{m}$ ) of the Borden water $\left(\varepsilon^{*}\right.$ ); and $\varepsilon^{*}$ comp refers to the relative permittivity (variable from approximately 19 to 27 ) of the sand-water composite $\left(\varepsilon^{*}\right.$ s-water $)$ modeled from the pre-injection GPR data at each horizon. Assuming spherical matrix particles and full saturation of the aquifer, fractional porosity of the pre-injection watersaturated sand is calculated for every GPR model location (Figure 1, curve A-B). Table 2 summarizes the results of these pre-injection fractional porosity calculations, and Figure 10 shows the pre-injection porosity distribution in the modeled area of the cell (complete porosity calculation results available in Sneddon, 2001). Depth to bottom of a given layer varies according to location within the cell. GPRinterpreted porosity values are not direct input to the flow model, but are used by flow modelers to estimate the initial pre-injection permeability field through iterative forward modeling and optimization of parameters.

Once the injection of DNAPL begins, and assuming there is no air in the system, the aquifer becomes a three-phase system of sand, water, and DNAPL. Assuming that fluid type, movement, and replacement does not change the soil porosity, that sand is always the matrix, and that porosity is always fully fluid saturated, another iteration of the BHS is applied to determine $\varepsilon^{*}{ }_{\text {comp }}$, which now refers to the relative permittivity of the sand-DNAPL composite ( $\varepsilon^{*}{ }_{\text {s-DNAPL }}$ ) (Figure 1 , curve B-C). At a given porosity determined from the pre-injection BHS water-sand curve (Figure 1, curve A-B), $\varepsilon^{*}{ }_{\text {s-water }}$ and $\varepsilon^{*}{ }_{\text {s-DNAPL }}$ define the end members of $\varepsilon^{*}{ }_{\text {matrix }}$ and $\varepsilon^{*}$ fluid, respectively, for additional iterations of the BHS (Figure 1, 

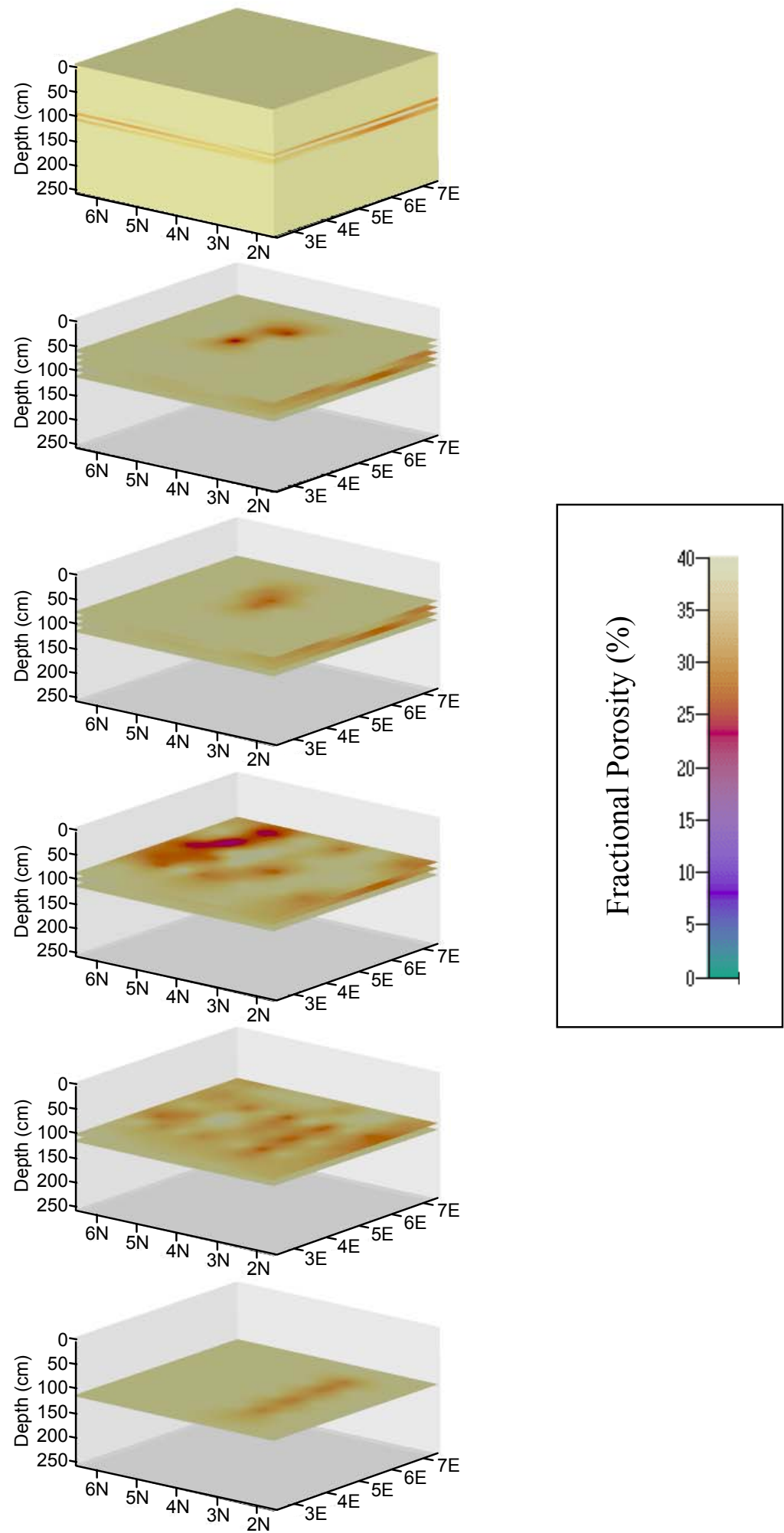

Fig. 10. Modeled variations in porosity of Borden sand within a subvolume of the cell. This model is calculated using the BHS formula applied to relative dielectric permittivity values interpreted from interactive forward modeling of the pre-injection GPR data. 
curve D-E). The new $\varepsilon^{*}$ comp of the sand-water-DNAPL composite $\left(\varepsilon^{*}{ }_{\text {s-water-DNAPL }}\right)$ is determined from modeling the GPR response as DNAPL is injected into the cell and displaces water. Variations in the values of the post-injection composite $\varepsilon^{*}{ }_{\text {s-water-DNAPL }}$ are now assumed to be due to the introduction of DNAPL by displacement of water rather than to variations in porosity and solving for (1- $\phi)$ is then equivalent to solving for percent DNAPL saturation (Figure 1, final BHS curve E-D).

Using the process described above, DNAPL saturations throughout a subvolume of the Borden cell were calculated from the GPR data acquired at 14 and 22 hours after the start of injection (complete saturation calculation results available in Sneddon, 2001). Vertical profile views of these PCE saturation models at the location of line 4E are shown in Figure 11a. This view allows direct comparison with the regularized GPR profile images of Figure 3. These GPR-interpreted PCE saturation values are provided as calibration data for 3-D, multiphase flow modeling.

\section{3-D MULTIPHASE FLOW MODELING}

Multiphase flow modeling has its origins in the oil industry (overviews provided by Crichlow 1977; Peaceman 1977), but has rapidly found use in the field of environmentally related modeling of nonaqueous phase liquids. Three-dimensional, multiphase contaminant transport modeling programs have been developed over the past decade (Faust 1985; Faust and others 1989; Letniowski and Forsyth 1991; Huyakorn and others 1994; and Gerhard 1995) to address this application. Because DNAPLs form longterm and complex contaminant source zones, accurate determination of location and prediction of DNAPL movement are critical to successful remediation efforts.

Calibrating multiphase flow models to match field core data is difficult due to uncertainties associated with the properties and continuity of subsurface units that may occur between locations of core samples, the collection of which often risks remobilization of DNAPL. For this reason, use of GPR data is an attractive alternative because it is noninvasive and provides a detailed continuous 3-D view of the subsurface. The dynamics of multiphase flow through a matrix of material with heterogeneous porosity, hydraulic permeability, and chemistry are, however, difficult to accurately simulate; and the effects of assumptions and simplifications are not easily determined, as discussed by Zheng and Bennett (1995, page 375). Initial work using the Borden 500-MHz GPR data set to calibrate a 3-D, multiphase flow model is described in Sander (1994). The computer code used in that work was abandoned after several attempts to execute it led to inconsistent and unsuccessful results. An alternative commercial code was considered before we were presented with an opportunity to use an available research code. The program 3D2PHASE, described by Gerhard (1995), was offered with support from the author. 3D2PHASE is an extension of a two-dimensional multiphase flow modeling program developed by Kueper and Frind (1991a,b), incorporating capillary-pressure hysteresis effects and formulated in terms of wetting phase pressure and saturation. Details of the program can be found in Gerhard (1995).

To optimize hydraulic permeabilities, the forward modeling program 3D2PHASE was executed from the universal inversion code (UCODE) developed by Poeter and Hill (1998). UCODE uses nonlinear regression to iteratively update the input parameters of the forward modeling program to optimize the match between the simulated fluid flow and the GPRinterpreted PCE saturation values at 14 and 22 hours. If the GPR-interpreted saturation values are accurate representations of the true subsurface values and the multiphase flow model is an appropriate representation of the multiphase flow process, then this inversion would result in parameter values approaching true subsurface properties.

In the inverse problem, distribution of the dependent variable (PCE saturation in this case) is the most well known aspect of the system while the distributions of the independent variable (in this case, 
pre-injection porosity and its associated intrinsic permeability) are less well known. Calibration is the process of manipulating the independent variable values to best match the simulated distribution of the dependent variable (fluid-flow simulated saturations) to the observation data (GPR-interpreted saturations). Calibration is an iterative process at multiple levels. The fluid-flow modeler iteratively establishes improved model frameworks (e.g., numbers and geometry of layers; formulation of the pressure/saturation relationship) within which a nonlinear regression algorithm iteratively varies parameter values to estimate the optimal values to minimize the residual between simulated saturations and GPR-interpreted saturations. In some instances, the residuals are biased in space or time, or may be nonrandomly distributed. Such a situation suggests that the underlying model framework is not representative of field conditions; this may be due to errors in the development of the fluid-flow model framework, due to assumption violations in use of the fluid-flow simulation code, or due to errors in the GPR interpretation. In such a case, the questionable points are re-examined; the GPR data may be remodeled for some points, the framework is redefined, and the fluid-flow inversion is repeated. Multiphase flow modeling results presented here result from inversion of a multiphase flow simulation based on a five layer GPR-interpreted geologic model. Varying fluid-flow geologic models and formulation of the pressure/saturation relationship will affect estimated multiphase flow parameters, resulting in varied simulated saturation results.
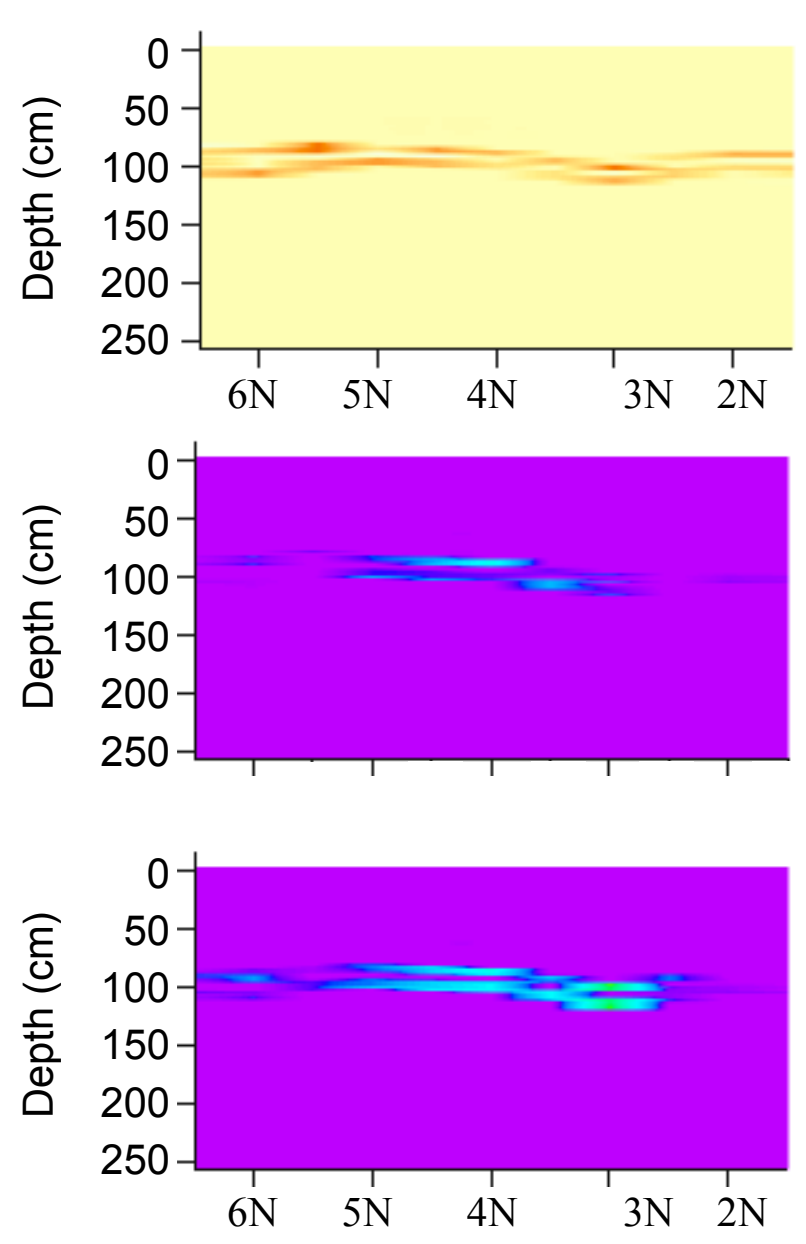

(a)
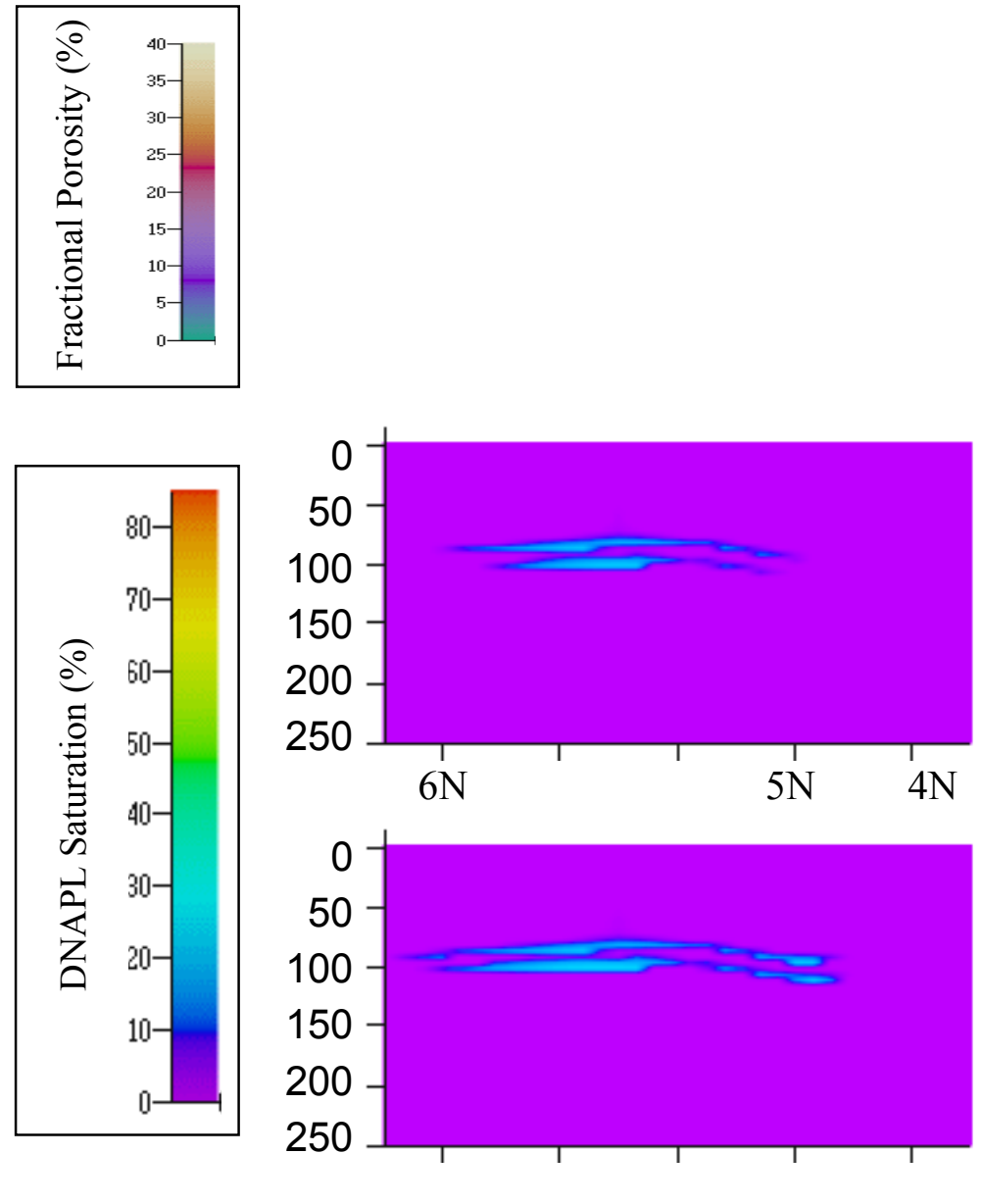

(b)

Fig. 11. On the left (11a), a vertical slice along the location of line 4E is shown of the GPR-interpreted pre-injection porosity at top; DNAPL saturation at 14 hours (middle) and 22 hours (bottom). On the right (11b), the same vertical slice is shown of the simulated multiphase flow model saturation values at 14 hours (top) and 22 hours (bottom). 
The final GPR-interpreted porosity model (Figure 10), and the final GPR-interpreted PCE saturation models for 14 and 22 hours (Figures 11, 12, and 13), are instrumental in defining an initial geologic model and calibration parameters for the multiphase flow simulation (Figure 1). As these available values were utilized in this research, they were not used as direct input to the multiphase flow model. 3D2PHASE assumes a constant porosity model with varying hydraulic permeability while GPR interpretation provides a starting model varying in porosity and does not describe variations in terms of hydraulic permeability. The challenge for the fluid flow modeler is to develop a relationship between variations in porosity and hydraulic permeability that will result in a simulation match to the saturation data. Additionally, the fluid flow model is defined with cell sizes of $15 \mathrm{~cm}$ laterally and $5 \mathrm{~cm}$ vertically while the GPR data was interpreted at spacings of $50 \mathrm{~cm}$ laterally and $1 \mathrm{~cm}$ vertically. As a result, the fluid flow modeler re-interprets the geologic model provided by the GPR interpretation from a $1-\mathrm{cm}$ depth scale to a $5-\mathrm{cm}$ depth scale and from a $50-\mathrm{cm}$ to a $15-\mathrm{cm}$ lateral scale, requiring averaging and interpolation of the original data. Simulation of the PCE injection, using 3D2PHASE with the optimal values determined by the inversion, yields values of PCE saturation for every $15-\mathrm{cm} \times 5-\mathrm{cm}$ cell at each specified time (Figures 11, 12, and 13).

\section{Limitations}

The inherent limitation of any model simulation of a natural system is that the representation is nonunique. Oreskes and others (1994) discuss some of the reasons for this and the implications of this premise on considering results of numerical models. Fluid-flow models are nonunique because input parameters, such as the number of layers, their geometry, hydraulic permeability, and porosity, are incompletely known due to sparsity of data, uncertainty associated with their measurement or interpretation (in the case of GPR), and/or loss of resolution due to averaging or interpolation of input parameters. We can attempt to minimize some of these limitations by providing GPR-interpreted values on a finer lateral grid (and simulating multiphase flow on a finer vertical grid), and by constraining GPR modeling parameters with as much other available data as possible.

\section{RESULTS}

Visual comparison of GPR-interpreted and multiphase flow-simulated saturations requires output data to be presented in proportional volumetric formats. Multiphase flow simulation output is defined in $5-\mathrm{cm} \times 5-\mathrm{cm}$ cubes within the 5-m x 5-m model domain to a depth of $2.5 \mathrm{~m}$. GPR-interpreted permeability, porosity, and saturation models are defined along discrete traces spaced $0.5 \mathrm{~m}$ apart within the 5-m x 5-m model domain with centimeter depth resolution to $2.5 \mathrm{~m}$. In preparation for visual comparison, each set of GPR-interpreted results was first interpolated along profile views with a quadratic Kriging routine (Cressie 1991) using an anisotropy ratio and search ellipse reflecting greater layer continuity in the horizontal east-west dimension over the north-south or vertical dimensions (Brewster and others 1995). Common depth points, in centimeter increments, for all profiles within a grouping of GPR-interpreted results were then interpolated between with a similar quadratic Kriging routine assuming no horizontal anisotropy among common depth points. On completion of interpolating GPR-interpreted data sets between traces and among common depth points, results are defined in 1-cm x 1-cm cubes. The $5-\mathrm{cm} \times 5-\mathrm{cm}$ resolution multiphase flow simulation data sets and the $1-\mathrm{cm} \times 1-\mathrm{cm}$ resolution GPRinterpreted data sets are then each interpolated identically within the volumetric visualization routine.

Figure 11 compares the GPR-interpreted saturation values and the output of the fluid-flow modeling along a vertical profile of the test volume at a location coincident with line 4E of the GPR field data. The match between the two saturation profiles could be improved, but is good in terms of general rate of migration, extent, and location of PCE accumulation. A volumetric comparison is presented in Figures 12 and 13 for 14 and 22 hours post-injection respectively. As seen in the profile view, there are strong similarities in general rate of flow, extent, and location of PCE accumulation as well as lateral and vertical spreading. The inferred channel shows well in the deepest of the horizontal slices of both models 


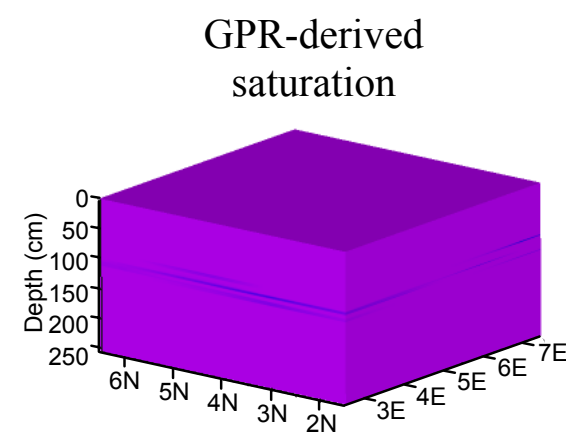

\section{Simulated}

saturation
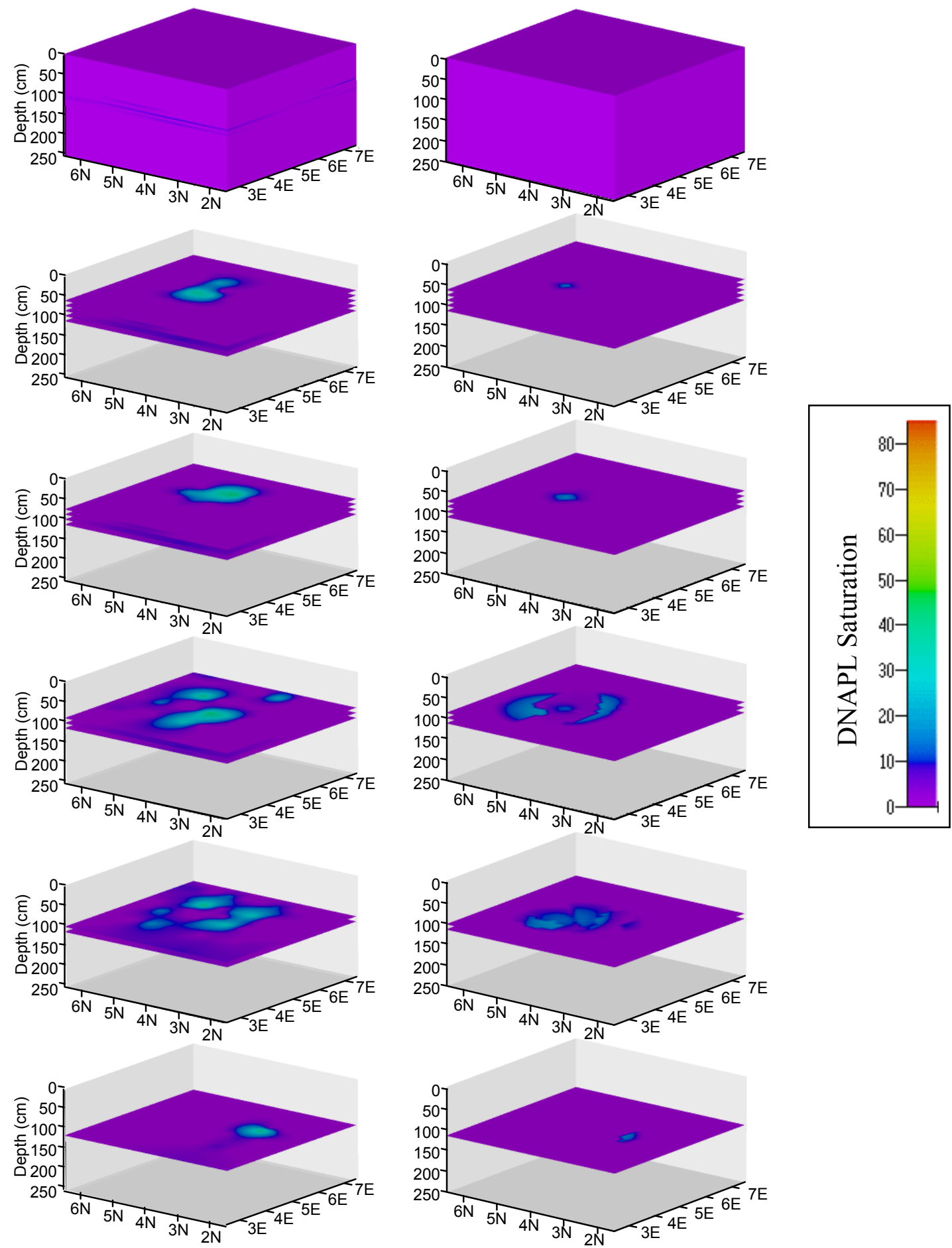

Fig. 12. The column on the left shows the GPR- interpreted DNAPL saturation in the modeled subvolume at 14 hours post-injection. The column on the right shows the DNAPL saturation in the same subvolume results of multiphase flow modeling at 14 hours. 

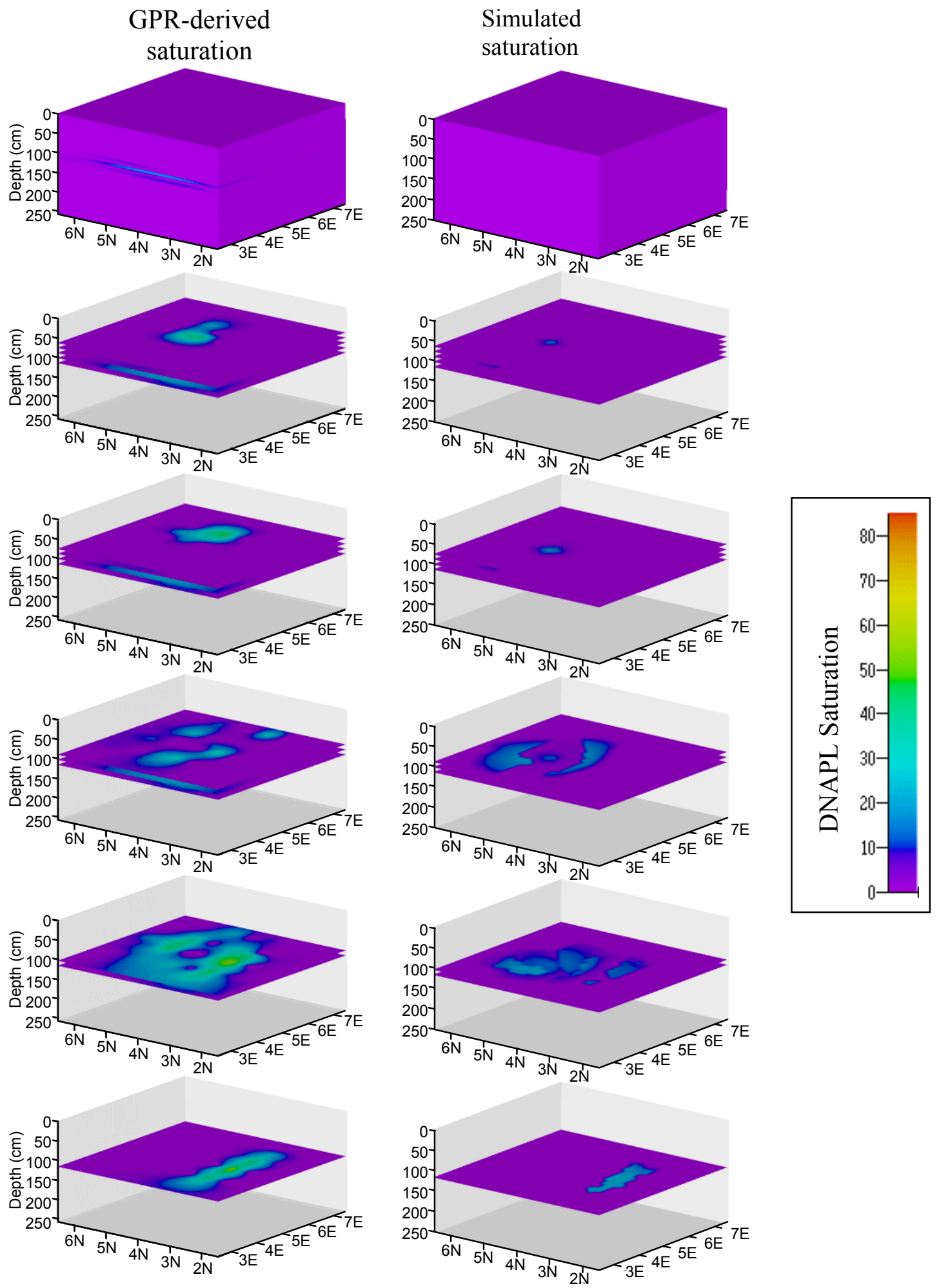

Fig. 13. The column on the left shows the GPR- interpreted DNAPL saturation in the modeled subvolume at 22 hours post-injection. The column on the right shows the DNAPL saturation in the same subvolume results of multiphase flow modeling at 22 hours. 
with PCE beginning to fill this linear feature at 22 hours. In the GPR-interpreted model, however, more PCE has filled the channel at that time.

In general, the GPR- interpreted model appears to show PCE spreading laterally and vertically at a slightly faster rate than simulated by the multiphase flow model, suggesting that the processes governing DNAPL flow and accumulation in the Borden cell seen in the GPR data are not yet fully represented by the multiphase flow model. This may be a function of the translation from GPR-available

parameters and geometry to multiphase flow parameters, or due to limitations or assumption violations of the multiphase flow modeling code in this particular application to the Borden cell. Another possibility is that due to amplitude focusing in the channel and 3-D effects in the data, 1-D modeling of GPR data does not yield sufficiently accurate calibration parameters for the fluid flow modeling to simulate; it does, however, provide more detailed information on location, accumulation, and relative saturation of DNAPL in the subsurface than is possibly available from core or well data alone.

\section{DISCUSSION}

All data, modeling, and simulation efforts presented here are attempts to better understand and characterize DNAPL behavior in an incompletely known subsurface. There are assumptions and limitations inherent in every step of the process from data acquisition through presentation of interpolated model results. Improvements to every step of the process are possible. The current effort facilitates understanding of the limitations while constraining the assumptions with independently available information. The GPR modeling process relies on many assumptions, as does the multiphase fluid flow simulation process. In spite of these, GPR interpretation produces a solution that fits the data and provides geologic and material property detail that is simplified in the multiphase flow simulation process to result in a reasonable resemblance of the simulated flow to GPR observations.

Efficiently providing a useful GPR-derived calibration data set for successful multiphase flow simulation requires a high level of communication between the two disciplines. Ideally, this dialogue commences prior to GPR data collection and continues throughout the interpretation process. In the data collection phase, a knowledgeable multiphase flow modeler may provide insights into the scale (horizontal extent and depth resolution) as well as density of GPR lines desirable to effectively sample the suspected zone of contamination and areas favored for calibration of the multiphase flow simulation. Upon viewing the collected data, the GPR practitioner may provide additional insights into actual zones of significant DNAPL accumulation, which may have been otherwise undersampled in calibration. Working together, the multiphase flow modeler and the GPR modeler may determine the most efficient density and location of GPR traces to be modeled and interpreted for porosity and DNAPL saturation values sufficient for successful calibration of the utilized multiphase flow simulation code. Also working together, the flow modeler and the GPR modeler may determine the optimized depth window and resolution to be modeled (i.e., it is not efficient for the GPR modeler to resolve 15 fine-scale layers if the multiphase simulation code is optimized for 5 coarse-scale layers). Once multiphase flow simulation and inversion is performed, examination of residuals and biases in the data may elucidate areas that warrant further GPR interpretation. Ideally, the dialogue continues until the process is complete.

This type of dialogue determined the model domain and led to the simplified five layer conceptual model of the Borden cell used in research presented here. In this case, simplification of the GPR resolution is both a benefit and a detriment to the outcome of the multiphase flow simulation as it is unlikely that the geometric arrangement of earth properties is simple at this scale. In previous DNAPL infiltration experiments conducted in the Borden aquifer, intricate interfingering of PCE along zones of variable permeability was observed (Poulson and Kueper 1992; Kueper and others 1992).

This type of dialogue also led to the aspiration for a more robust GPR data interpretation, available through existing geophysical technology. A cursory review of the vast literature on the use of seismic data to delineate oil fields suggests alternate methods (Kettle 1985; Horvath 1985). One preferred method to produce the desired GPR data set for porosity and saturation interpretation consists of: 1) carefully processing the data to remove the variable near-field effects on the starting pulse; 2) correcting 
for variable lateral positioning, timing, and gain; and 3) migrating the data in a manner that best preserves variations in geology within the final waveforms. For data presented here, steps 1) and 2) have already been performed, as has the preliminary velocity analysis required to perform migration. Migration is velocity modeling in $2-\mathrm{D}$ or $3-\mathrm{D}$, similar to what was performed on this data in 1-D. The Borden data set requires a full 3-D migration to best interpret the final waveform (Olhoeft 1994). Processing and migration is not trivial and must include all geological information from well control and other sources. Oil industry case histories, however, indicate that migration results can be accurate enough to extract detailed geology from the data (Hardage and others 1994; Connelly and others 1991; Morse and others 1987; Dahm and Graebner 1982). The information produced by processing and migration could include values of porosity and DNAPL saturation on a grid with the density of the GPR data, and not the relatively sparse density of the significant interactive forward modeling effort presented here. Moreover, migration is the only way to remove focusing effects of the subsurface geometry from the waveform amplitudes. Without this, the amplitude variations due to geometrical effects are falsely interpreted as material property contrasts.

Additionally, the dialogue between multiphase modeler and GPR modeler led to the aspiration for improvements in the 3-D multiphase flow modeling effort. Though 3D2PHASE remains our best choice, in its current form it requires a uniform porosity throughout the model (allowing for variable permeability). The GPR interpretation provides a variable porosity model which, due to the constraints of 3D2PHASE, are not used as direct input to the model, but are used only indirectly to estimate the starting model permeability field. Input of variable porosity would produce a different distribution of DNAPL saturation for the same volume of DNAPL. The differences in saturation would influence the relative permeability and thus the final distribution. As another consideration, 3D2PHASE is based on the Brooks-Corey formulation for capillary pressure/saturation relationship (Brooks and Corey 1966). Alternative capillary pressure/saturation models have been shown to produce substantially different DNAPL spreading patterns (Rathfelder and Abriola 1998) and may produce a better fit to the GPRinterpreted saturations.

\section{CONCLUSIONS}

Though there is need for improvement of GPR interpretation and multiphase flow modeling for practical applications, this research has enhanced our ability to assess and monitor DNAPL contaminated sites. One-dimensional full-waveform GPR modeling coupled with recursive applications of the BHS mixing formula can quantify porosity and DNAPL saturation. These DNAPL saturations can be used as observations to invert multiphase flow models.

There are advantages in using GPR to detect DNAPLs, but the GPR user must also be aware of its limitations. Such limitations include: the need to repetitively collect GPR data during DNAPL movement, difficulties in the quantitative interpretation of DNAPL saturation, and the interference of adverse site conditions such as high mineralogical clay content with GPR data collection. In spite of these, the GPR- interpreted DNAPL saturations are of value to the fluid-flow modelers. While the limitations are undesirable, GPR data provide substantially more spatially dense information about DNAPL movement and accumulation in the subsurface than alternative invasive methods, without the additional risk of contaminant remobilization.

Combining the skills of GPR practitioners with those of multiphase flow modelers can improve the results obtained by both disciplines. As consumers of GPR surveys, flow modelers demand highly detailed and accurate subsurface information, challenging GPR geophysicists to improve both data acquisition and interpretation. This research contributes to the continuing effort to improve both GPRinterpreted information and multiphase flow algorithms. 


\section{ACKNOWLEDGEMENT AND DISCLAIMER}

The U.S. Environmental Protection Agency through interagency agreement \#DW14936568-01-0 to the USGS has funded the research described in this paper, but it has not been subjected to the Agency review. Therefore, it does not necessarily reflect the views of the Agency. Mention of trade names or commercial products does not constitute endorsement or recommendation for use.

We would like to acknowledge the work of Gary Olhoeft in initiating this project and helping to see it to completion. Louise Pellerin, Kathy Sander, Terrie Rowley, Jeff Lucius, and Vic Labson have also played active roles on this project at various times, and we acknowledge and appreciate their efforts.

We especially acknowledge the enduring support and patience of Aldo Mazzella who made this work possible. He is much appreciated.

\section{REFERENCES}

Annan, A. P., Bauman, P., Greenhouse, J. P., and Redman, J. D., 1991, Geophysics and DNAPLs: Ground Water Management No. 5, Fifth National Outdoor Action Conference on Aquifer Restoration, Ground Water Monitoring and Geophysical Methods, Nat. Wat. Well. Assn., 963977.

Bauman, P., 1989, A detailed geophysical investigation of a shallow sandy aquifer: M.Sc. thesis, Univ. of Waterloo.

Bohla, J., Jr., 1986, A sedimentological investigation of a progradational foreshore sequence: C.F.B. Borden: M.Sc. thesis, Univ. of Waterloo.

Brewster, M. L., and Annan, A. P., 1994, Ground-penetrating radar monitoring of a controlled DNAPL release: $200 \mathrm{MHz}$ radar: Geophysics, 59, 1211-1221.

Brewster, M. L., Annan, A. P., Greenhouse, J. P., Kueper, B. H., Olhoeft, G. R., Redman, J. D. and Sander, K. A., 1995, Observed migration of a controlled DNAPL release by geophysical methods: Ground Water, 33, 977-987.

Brewster, M. L., Redman, J. D., and Annan, A. P., 1992, Monitoring a controlled injection of perchloroethylene in a sandy aquifer with ground penetrating radar and time domain reflectometry: Symposium on the Application of Geophysics to Environmental and Engineering Problems, Env. and Eng. Geophys. Soc., 611-618.

Brooks, L. J. and A. T. Corey, 1966, Properties of porous media affecting fluid flow. Journal of Irrigation and Drainage Division, ASCE, 92, 61-88.

Bruggeman, D. A. G., 1935, Berechnung Verschiedener Physikalischer Konstanten von Hetarogenen Substanzen: Ann. Phys. Lpz., 24, 636-679.

Connelly, D. L., Ferris, B. J. and Trembly, L. D., 1991, Northwestern Williston Basin case histories with 3-D seismic data: Geophysics, 56, 1849-1874.

Cressie, N. A. C., 1991, Statistics for spatial data: John Wiley and Sons, Inc.

Crichlow, H. B., 1977, Modern reservoir engineering - a simulation approach: Prentice-Hall Inc.

Dahm, C. G. and Graebner, R. J., 1982, Field development with three-dimensional seismic methods in The Gulf of Thailand - A case-history: Geophysics, 47, 149-176.

Duke, S., 1990, Calibration of ground penetrating radar and calculation of attenuation and dielectric permittivity versus depth. M.Sc. thesis, Colorado School of Mines.

Faust, C. R., 1985, Transport of immiscible fluids within and below the unsaturated zone: a numerical model: Water Resources Research, 21, 587-596.

Faust, C. R., Guswa, J. H., and Mercer, J. W., 1989, Simulation of three-dimensional flow of immiscible fluids within and below the unsaturated zone: a numerical model: Water Resources Research, 25, 2449-2464.

Gerhard, J. I., B. H. Kueper, and G. R. Hecox, 1998, The Influence of Waterflood Design on the Recovery of Mobile DNAPLs. Ground Water, 36(2), 283-292. 
Greenhouse, J., Brewster, M., Schneider, G., Redman, D., Annan, P., Olhoeft, G., Lucius, J. E., Sander, K., Mazzella, A., 1993, Geophysics and Solvents: The Borden experiment: The Leading Edge, 12, No. 4, 261-267.

Hanai, T., 1968, Electrical properties of emulsions, in Sherman, P., Ed., Emulsion science: Academic Press.

Hardage, B. A., Levey, R. A., Pendleton, V., Simmons, J. and Edson, R., 1994, 3-D seismic case history evaluating fluvially deposited thin-bed reservoirs in a gas-producing property: Geophysics, 59, 1650-1665.

Horvath, P. S., 1985, The effectiveness of offshore three-dimensional seismic surveys - Case-histories: Geophysics, 50, 2411-2430.

Huyakorn, P. S., Panday, S., and Wu, Y. S., 1994, A three-dimensional multiphase flow model for assessing NAPL contamination in porous and fractured media: I. Formulation: Journal of Contaminant Hydrology, 16, 109-130.

Kettle, R. W., 1985, Fifty years of case-histories: Geophysics, 50, 2431-2442.

Kueper, B. H. and Frind, E. O., 1991a, Two-phase flow in heterogeneous porous media: 1. model development: Water Resources Research, 27, 1049-1057.

Kueper, B. H. and Frind, E. O., 1991b, Two-phase flow in heterogeneous porous media: 2. model application: Water Resources Research, 27, 1059-1070.

Kueper, B. H., Feenstra, S., Rivett, M. O., Cherry, J. A., 1992, A series of controlled field experiments to study DNAPL behavior: implications for site remediation: HAZMAT International, Hazardous Materials and Environmental Management Conference.

Kutrubes, D. L., 1986, Dielectric permittivity measurements of soils saturated with hazardous fluids: M. Sc. thesis, Colorado School of Mines.

Letniowski, F. W., and Forsyth, P. A., 1991, A control volume finite element method for three dimensional NAPL contamination: Internat. Jour. of Numer. Methods in Fluids, 13, 955-970.

Lucius, J. E., Olhoeft, G. R., Hill, P. L., and Duke, S. K., 1992, Properties and hazards of 108 selected substances - 1992 edition: U. S. Geological Survey Open File Report 92-527.

Morse, V. C., Johnson, J. H., Crittenden, J. L. and Anderson, T. D., 1987, Techniques for seismic delineation of complex structure - A case-history: Geophysics, 52, 802-809.

Olhoeft, G. R., 1992, Geophysical detection of hydrocarbon and organic chemical contamination: Symposium on the Application of Geophysics to Environmental and Engineering Problems, Env. and Eng. Geophys. Soc., 587-595.

Olhoeft, G. R., 1994, Modeling out-of-plane scattering effects: in Proc. of the Fifth Int'1. Conf. on Ground Penetrating Radar, 133-144.

Olhoeft, G. R., 1998, GRORADAR ${ }^{\text {TM}: ~ A c q u i s i t i o n, ~ p r o c e s s i n g, ~ m o d e l i n g, ~ a n d ~ d i s p l a y ~ o f ~ g r o u n d ~}$ penetrating radar data: ver. 4.0, software distributed on CD-ROM at Seventh Internat. Conf. on Ground Penetrating Radar, (http://www.g-p-r.com).

Oreskes, N., Shrader-Frechette, K., Belitz, K., 1994, Verification, validation and confirmation of numerical models in the earth sciences: Science, 263, 641-646.

Pankow, J. F., Feenstra, S., Cherry, J. A., Ryan, M. C., 1996, Dense chlorinated solvents in groundwater, background and history of the problem in Pankow, J. F., Cherry, J. A., in Eds., Dense Chlorinated Solvents and other DNAPLs in Groundwater; History, Behavior, and Remediation: Waterloo Press, 1-52.

Peaceman, D. W., 1977, Fundamentals of numerical reservoir simulation: Elsevier Science Publ. Co., Inc.

Poeter, E. P., and Hill, M. C., 1998, Documentation of UCODE, a computer code for universal inverse modeling: U.S. Geological Survey water-resources investigations report 98-4080.

Poulsen, M. M., and Kueper, B. H., 1992, A field experiment to study the behaviour of tetrachloroethylene in unsaturated porous media: Environmental Science and Technology, 26, 889-895.

Powers, M. H., 1995, Dispersive ground penetrating radar modeling in 2D: Ph.D. thesis, Colorado School of Mines. 
Powers, M.H. and Olhoeft, G. R., 1995, GPRMODV2: one-dimensional full waveform forward modeling of dispersive ground penetrating radar data, version 2.0: U.S. Geological Survey Open File Report 95-58, 41p. + floppy diskette.Rathfelder, K., and Abriola, L. M., 1998, The influence of capillarity in numerical modeling of organic liquid redistribution in two-phase systems: Advances in Water Resources, 21, 159-170.

Rathfelder, K., and Abriola, L. M., 1998, The influence of capillarity in numerical modeling of organic liquid redistribution in two-phase systems, Adv. Water Resour., 21(2), 159-170.

Redman, J. D., 1992, Geophysics and the Solvents-in-Groundwater Program: Symposium on the Application of Geophysics to Environmental and Engineering Problems, Env. and Eng. Geophys. Soc., 375-382.

Redman, J. D., Kueper, B.H., and Annan, A. P., 1991, Dielectric stratigraphy of a DNAPL spill and implications for detection with ground penetrating radar: Ground Water Management No. 5, Fifth National Outdoor Action Conference on Aquifer Restoration, Ground Water Monitoring and Geophysical Methods, Nat. Wat. Well. Assn., 1017-1030.

Redman, J. D., and Annan, A. P., 1992, Dielectric permittivity monitoring in a sandy aquifer following the controlled release of DNAPL: Fourth Internat. Conf. on Ground Penetrating Radar, 191-195.

Sander, K. A., Olhoeft, G. R., and Lucius, J. E., 1992, Surface and borehole radar monitoring of a DNAPL spill in 3D versus frequency, look angle and time: Symposium on the Application of Geophysics to Environmental and Engineering Problems, Env. and Eng. Geophys. Soc., 455-469.

Sander, K. A., 1994, Characterization of DNAPL Movement in Saturated Porous media Using Ground Penetrating Radar: M.Sc. thesis, Colorado School of Mines.

Sander, K. A., and Olhoeft, G. R., 1994, 500-MHz ground penetrating radar data collected during an intentional spill of tetrachloroethylene at Canadian Forces Base Borden in 1991: U.S.G.S. Digital Data Series DDS-25, CD-ROM.

Schneider, G. W., and Greenhouse, J. P., 1992, Geophysical detection of perchloroethylene in a sandy aquifer using resistivity and nuclear logging techniques: Symposium on the Application of Geophysics to Environmental and Engineering Problems, Env. and Eng. Geophys. Soc., 619-628.

Sen, P. N., Scala, C., and Cohen, M. H., 1981, A self-similar model for sedimentary rocks with application to the dielectric constant of fused glass beads: Geophysics, 46, 781-795.

Sihvola, A. H., 1999, Electromagnetic mixing formulas and applications: IEEE electromagnetic waves series 47: Institution of Electrical Engineers, London.

Sneddon, K. W., Olhoeft, G. R., and Powers, M. H., 2000, Determining and mapping DNAPL saturation values from noninvasive GPR measurements: Symposium on the Application of Geophysics to Environmental and Engineering Problems, Env. and Eng. Geophys. Soc., 293-303.

Sneddon, K. W., 2001, Determination of porosity and DNAPL saturation values from modeling of noninvasive ground penetrating radar data: M.Sc. thesis, Colorado School of Mines.

Topp, G. C., Davis, J. L., and Annan, A. P., 1980, Electromagnetic determination of soil water content: Measurements in coaxial transmission lines: Water Resources Research 16, 574-582.

Zheng, C. and Bennett, G. D., 1995, Applied contaminant transport modeling: theory and practice: Van Nostrand Reinhold, New York. 